\title{
Remarks on Nominal Inflection in German
}

\section{Gereon Müller}

\section{IDS Mannheim}

\section{Introduction}

Any theory of nominal inflection has to fulfil two tasks for a given language. First, the inventory of inflection markers has to be determined; and second, the syntactic distribution of these markers has to be accounted for. Typically, the latter task is handled within the syntactic component of a grammar, whereas the former task is addressed in a morphological (or lexical) component that is pre- or postsyntactic, and that relies on the notion of paradigm as an inventory of inflection markers that exists independently of syntax. The analysis of nominal inflection in German that I want to develop in this article deviates from standard approaches in that it is based on the assumption that both the form of inflection markers, and their distribution, is exclusively determined in the syntactic component of grammar. Consequently, the notion of paradigm emerges as an epiphenomenon without theoretical significance.

Much recent work on nominal inflection in German incorporates the idea that competition plays an important role in nominal inflection, in the guise of the Specificity Principle that forces the choice of the most specific form among a class of competing candidates that are all otherwise well formed. ${ }^{1}$ The Specificity Principle has been employed both for the determination of the inventory of inflection markers (see Blevins 1995, Wunderlich 1996; 1997a; 1997b, and Wiese 1996; 1999), and for the distribution of inflection markers in syntax (see Gallmann 1996; 1998). I think that a competition-based approach is indeed on the right track. However, I will move from a specificity-based to an optimality-theoretic approach (see Prince \& Smolensky 1993), according to which a candidate qualifies as optimal (i.e., grammatical) if it best satisfies a set of violable and ranked constraints. The optimality-theoretic analysis of German nominal inflection will be shown to have three desirable consequences. First, paradigmatic syncretism among nominal inflection markers can be explained in its full generality. Second, by adopting the sonority hierarchy as a set of violable constraints with a fixed internal ranking, a partial motivation can be given for the make-up of the German nominal inflection marker inventory. And third, by optimizing the form and the distribution of inflection markers simultaneously, cases where the syntactic context seems to directly determine the choice of inflection marker can be accounted for.

In addition to the simultaneous determination of the form and the distribution of inflection markers and the optimality-theoretic perspective, the present approach has a third conspicuous property that separates it from most existing analyses: Standardly, nominal inflection is brought about by positive constraints that demand a certain inflection marker for a given

\footnotetext{
${ }^{1}$ Also compare the Blocking Principle (see Williams 1997 and references cited there) and the Elsewhere Condition (see Kiparsky 1982, among others).
} 
specification of morpho-syntactic features. In contrast, I would like to suggest that nominal inflection mainly results from negative constraints: first, negative feature co-occurrence restrictions (FCRs; see Gazdar et al. 1985) that block certain types of inflection markers for a given specification of morpho-syntactic features, and second, the sonority hierarchy that demands a minimization of consonantal marking. Under this assumption, the question arises of why inflection markers can occur in the first place. In the present approach, there is a single reason: A high-ranked syntactic constraint, CASE, requires the presence of some Case marker on certain lexical categories. Most of the other constraints to be discussed below will then conspire to choose the optimal marker that minimizes their violation.

The approach to nominal inflection in German to be developed here can be viewed as being part of a more general research program within optimality theory, according to which the existence and the form of certain morphological objects are determined in the syntax, and not in a morphological or lexicon component. Such an approach has been pursued by Grimshaw $(1997 ; 2001)$ and Legendre, Smolensky \& Wilson (1998); the latter coin the slogan "The functional lexicon is slave to the syntax." Samek-Lodovici (2001) applies this approach to verbal agreement morphology, and Aissen (2000) and Müller (2001) to Case morphology - on purely syntactic grounds and independently of the present considerations. According to these latter two analyses, the need for morphological Case may arise in syntax, under a specific ranking of syntactic constraints. If it does, a Case marker is called for; if it does not, the presence of a Case marker is blocked by lower-ranked faithfulness constraints (since the Case marker, by assumption, is not part of the syntactic input). ${ }^{2,3}$

Based on such a system, it may suffice for present purposes to adopt the constraint CASE as the sole trigger for morphological Case, with the understanding that this constraint may in fact be derivable as a theorem from the interaction of a set of ranked constraints that impose further restrictions on the nature of NP (e.g., by demanding that NP shows up in a scrambling language, or that NP is animate, etc.).

(1) CASE:

a. The left edge of the minimal residue of an NP requires a Case marker.

b. The right edge of the minimal residue of an NP requires a Case marker.

\footnotetext{
${ }^{2}$ Despite this basic similarity, the two approaches differ significantly, most importantly with respect to the trigger for morphological Case that they identify. In Aissen's (2000) system, whether Case marking on object NPs must occur or not depends on the language-particular ranking of constraints referring to features like [ \pm animate] and $[ \pm$ definite], with animate and definite objects exhibiting a preference for Case marking as opposed to inanimate and indefinite objects. In contrast, in Müller (2001) I suggest that Case marking may be required under rankings that produce scrambling of NPs, i.e., in free word order languages. The two approaches are not necessarily incompatible; but I will not pursue this matter here.

${ }^{3}$ This type of optimality-theoretic approach to Case marking in syntax turns out to support two other features of the present approach, viz., the abandonment of paradigms as genuine linguistic objects, and the abandonment of constraints that require a specific form of inflection marker for a given morpho-syntactic specification. Thus, suppose for the sake of the argument that the need for Case marking is determined by syntactic constraints in the syntax, but Case inflection paradigms are formed independently. Then, the peculiar situation could arise that a language generates articulate Case paradigms without ever having a chance of using them, due to a syntactic ranking that strictly blocks the presence of Case markers. Similarly, suppose that the need for Case marking is determined by syntactic constraints in the syntax, but that there are also constraints that require certain Case markers for certain types of lexical categories. Then, a high ranking of the latter constraints could force the presence of a Case marker independently of the syntactic constraints, and thereby undermine their effects.
} 
Several clarifications are in order. First, here and henceforth, I assume that a Case marker cannot be phonologically empty; morphological Case is necessarily overt. ${ }^{4}$ Next, the notions of minimal residue and edge are based on Chomsky (1995; 2001), respectively, and can be defined as follows.

(2) a. Minimal Residue:

The minimal residue of an XP includes the head X (the head residue, HR) and specifiers of $X$ (the specifier residue, SR).

b. Edge:

(i) $\mathrm{Y}$ is at the left edge of the minimal residue of XP iff it is leftmost in SR.

(ii) $\mathrm{Y}$ is at the right edge of the minimal residue of XP iff it is rightmost in HR.

As for the structure of NP, I assume that DP, the phrase that contains the determiner, occupies a SpecN position, and that additional APs are located in further specifier positions that are made possible by the option of $\mathrm{N}^{\prime}$ recursion (see Chomsky 1995; 2001), as in (3). ${ }^{5}$

(3) $\left[\mathrm{NP}_{\mathrm{NP}}[\mathrm{DP}\right.$ dieser $]\left[\mathrm{N}_{\mathrm{N}^{\prime}}[\right.$ AP gute $]\left[\mathrm{N}^{\prime}[\right.$ AP alte $]\left[\mathrm{N}_{\mathrm{N}}\right.$ Tee $\left.\left.]\right]\right]$

this good old tea

The SR of NP in (3) contains dieser, gute, and alte; the HR of NP contains only Tee. Hence, dieser is at the left edge of the minimal residue of NP, and Tee is at the right edge of the minimal residue of NP. CASE then requires a Case marker on dieser and Tee, but not on gute and alte. Since dieser is indeed Case marked (the Case marker er is attached to the stem dies), we can conclude that CASE is indeed active in German, and not rendered inactive by higher-ranked constraints that ban Case markers in syntactic outputs (as is the case in languages like English and Bulgarian). ${ }^{6}$ Given that unforced Case marking is blocked, the inflection marking on gute and alte is initially surprising and in need of an explanation. Furthermore, Tee does not have any inflection marker whatsoever, which already suggests a violability of the right-edge requirement imposed by CASE. We will later see that the left-edge requirement must be violable as well. I assume that CASE is indeed violable, but gradient in the sense that violations can and must be kept minimal: If, e.g., there are a DP and an AP in the SR of an NP, and CASE must be violated with DP because of a higher-ranked constraint, the violation must be kept minimal by assigning a Case marker to AP (as in ein guter Tee 'a good tea'). Gradient violation is an option with the SR of an NP, but not with its HR, which contains only $\mathrm{N}$ : If $\mathrm{N}$ cannot bear a Case marker, adding a Case marker to a preceding adjective in SR will not help.

With these assumptions as background, I will now turn to the form and distribution of nominal inflection in German, proceeding from determiner inflection (section 2) to noun

\footnotetext{
${ }^{4}$ This is also a basic tenet of minimalist morphology (see Wunderlich 1996; 1997a) but not, e.g., of distributed morphology (see, e.g., Halle 1994).

${ }^{5}$ That said, given appropriate modifications of constraints like CASE, the gist of what follows could also be formulated under the (standard) assumption that DP dominates NP. That I adopt an NP-over-DP analysis instead is motivated partly by the fact that it allows a somewhat simpler account, without additional projections of unclear provenance, and partly by what I take to be a surprisingly small number of arguments for an DPover-NP analysis in German.

${ }^{6}$ To be sure, inflection marking of the left edge of a minimal residue takes place at the right edge of a lexical category in German, not at the left edge. This follows from whatever is responsible for the fact that inflection proceeds by suffixation in German, and will be ignored in what follows.
} 
inflection (section 3), and then to adjective inflection (section 4).

\section{Determiner inflection}

\subsection{Syncretism}

Consider $\mathrm{P}_{1}$, the paradigm for canonical cases of determiner inflection (or "pronominal inflection"), illustrated on the basis of the demonstrative determiner dies ('this'). ${ }^{7}$

$P_{1}$ : Determiner inflection

\begin{tabular}{|l|c|c|c|c|}
\hline dies & M.SG & N.SG & F.SG & PL \\
\hline \hline NOM & er & es & e & e \\
\hline ACC & en & es & e & e \\
\hline DAT & em & em & er & en \\
\hline GEN & es & es & er & er \\
\hline
\end{tabular}

The paradigm lists sixteen Case markers. ${ }^{8}$ Consequently, a naive approach can derive it by specifying sixteen constraints (or rules) that require a specific Case marker for each pairing of abstract Case and gender/number. However, there is a significant amount of syncretism: Each of the sixteen Case markers takes one out of only five forms: e, er, en, em or es. In view of this fact, it has often been assumed since Bierwisch (1967) that the number of constraints that are needed to account for the paradigm of determiner inflection can and should be reduced. To this end, Bierwisch argues that abstract Cases like NOM, ACC etc. should not be viewed as primitives, but can be derived by cross-classifying the morphosyntactic features [ \pm oblique] and $[ \pm$ governed]. A similar approach is proposed for gender, which is treated in terms of the morpho-syntactic features $[ \pm$ masc $]$ and $[ \pm$ fem $]$. If a featurebased approach of this type is adopted, the constraints that produce inflection paradigms do not have to refer to fully specified forms; they can also refer to underspecified forms that characterize natural classes, or they can apply without any specification. This way, many instances of syncretism can be accounted for. Underspecification implies that it will often be the case that more than one Case marker is initially compatible with a given complete morpho-syntactic specification; thus, a competition of Case markers may arise for a given cell in the paradigm. To ensure uniqueness of Case marker choice, the Specificity Principle can be employed; this meta-principle selects the most specific Case marker that is compatible with a given specification of morpho-syntactic features.

Approaches of this type have been developed by Bierwisch (1967), Blevins (1995), Wiese

\footnotetext{
${ }^{7}$ For expository purposes, I continue to use paradigms throughout this article. They function as generalizations that need to be derived and have no independent theoretical status. Here and in what follows, NOM stands for "nominative Case", ACC for "accusative Case", DAT for "dative Case", and GEN for "genitive Case". MASC stands for "masculine gender" and is sometimes abbreviated as M; similarly for FEM ("feminine gender"; F) and NEUT ("neuter gender"; N). Finally, SG stands for "singular", and PL for "plural".

${ }^{8}$ We would end up with twenty-four Case markers if we were to further classify plural forms with respect to gender. However, gender distinctions are neutralized in the plural in German, which makes such a complication unnecessary. Note that the NOM.NEUT, ACC.NEUT markers of the determiner dies can optionally be deleted. I assume this to be the result of a surface-oriented phonological operation that may apply in /s/-/s/ contexts; see Gallmann (1996) on why such deletion might be impossible in GEN environments.
} 
(1996; 1999), and Wunderlich (1997b). ${ }^{9}$ They all succeed in reducing the number of constraints needed to derive the sixteen-cell paradigm to below ten. However, none of these approaches manages to reduce the constraint number to what initially looks like the ideal size of five, i.e., the number of different forms. In other words: In all these approaches, several instances of syncretism remain accidental and unaccounted for. In particular, instances of syncretism with $e r$, en, and es continue to require a non-uniform treatment. In view of this, recourse can be made to a distinction between "systematic" and "non-systematic" (i.e., "accidental") instances of syncretism (see, e.g., Blevins 1995, 114, Wunderlich 1997b, 47, and Stump 2001, 215). Systematic syncretism requires a uniform treatment, non-systematic syncretism does not. There is one main argument for the assumption that the syncretism encountered with the Case markers er, en, and es in the determiner inflection paradigm is non-systematic: It is difficult to see how NOM.MASC, DAT.FEM, GEN.FEM, and GEN.PL specifications can be characterized as a natural class that can be referred to by a single constraint that determines the occurrence of the Case marker er; how ACC.MASC and DAT.PL specifications can form a natural class that is used by a constraint that delivers the Case marker en; and how NOM.NEUT, ACC.NEUT, GEN.MASC, and GEN.NEUT specifications can form a natural class used by a constraint yielding es (see Bierwisch 1967, 246). ${ }^{10}$

This argument is valid. However, it relies on the premises that (i) only natural classes determined by common features can be referred to by the constraints regulating the distribution of Case markers, and that (ii) these constraints must tell us what a Case markers looks like for a given morpho-syntactic specification. Suppose now that these two assumptions are abandoned, and replaced by the following assumptions: (i) In addition to natural classes determined by common features (e.g., $[+x,-y]$ ), the complements of these natural classes (e.g., $\neg[+\mathrm{x},-\mathrm{y}]$ ) can also be referred to. (ii) There are no constraints that demand a specific Case marker for a given morpho-syntactic specification, only FCRs that block Case markers in certain contexts. As we will see, it turns out that these alternative assumptions, together with the general optimality-theoretic hypothesis of violable and ranked constraints, make it possible to consider all syncretism in the domain of determiner inflection systematic. If tenable, such an approach strikes me as more attractive: That two (or more) occurrences of a single form have a common raison d'être should be the null hypothesis, both for the language

\footnotetext{
${ }^{9}$ Note, however, that the Specificity Principle is not yet used by Bierwisch, who relies on extrinsic ordering, which produces equivalent results. Wiese uses both the Specificity Principle and extrinsic ordering (albeit one which he provides independent motivation for). Blevins and Wunderlich employ only a version of the Specificity Principle.

${ }^{10}$ The literature also contains other arguments for non-systematic syncretism in determiner inflection. E.g., Wiese $(1999,8)$ observes that the homonymy of dieses as a realization of NOM.NEUT, ACC.NEUT on the one hand, and GEN.MASC, GEN.NEUT on the other, breaks down with the (otherwise similar) definite article, where the former is realized as das, and the latter as des. He concludes that this might be taken as an argument for the presence of non-systematic syncretism with dieses. Furthermore, Wiese, Eisenberg (2000, 165), and Zifonun $(2001,39)$ assume that syncretism with determiners can only be systematic if it is not resolvable in complete NPs that also contain A and N. From this it follows that, e.g., we are dealing with non-systematic syncretism in the case of dieses as a realization of NOM.NEUT and dieses as a realization of GEN.NEUT (compare dieses alte Buch 'this old book nom ' with dieses alten Buches 'this old book ${ }_{\text {gen }}$ '). I find arguments of this type dubious: If a sufficient amount of (contextual or other) information is added, all ambiguity can be resolved, and we should in fact expect all syncretism to be non-systematic; compare, e.g., diesem alten Mann, der ... ('this old man ${ }_{a c c}$ who') with diesem alten Buch, das ... ('this old book ${ }_{a c c}$ that').
} 
learner and the linguist.

\subsection{Proposal}

Let me begin by making explicit my assumptions about the decomposition of Case, gender, and number into primitive morpho-syntactic features; see (4).

(4)

$\begin{array}{ll}\text { Case } & \\ \text { NOM: } & {[-\mathrm{obl},- \text { gov }]} \\ \text { ACC: } & {[-\mathrm{obl},+ \text { gov }]} \\ \text { DAT: } & {[+\mathrm{obl},+ \text { gov }]} \\ \text { GEN: } & {[+\mathrm{obl},- \text { gov }]}\end{array}$

Gender/Number

$\begin{array}{ll}\text { MASC: } & {[+ \text { masc },- \text { fem }]} \\ \text { FEM: } & {[- \text { masc },+ \text { fem }]} \\ \text { NEUT: } & {[+ \text { masc },+ \text { fem }]} \\ \text { PL: } & {[- \text { masc },- \text { fem }]}\end{array}$

The Case system adopted here is that of Bierwisch (1967): DAT and ACC are governed, NOM and GEN are ungoverned; DAT and GEN are oblique, and NOM and ACC are non-oblique. The gender/number system is also similar to what is suggested by Bierwisch (1967): MASC is [+masc,-fem], FEM is [-masc, + fem]. However, I will deviate from Bierwisch's original proposal and follow Wiese $(1996 ; 1999)$ in assuming that NEUT is $[+$ masc, + fem $]$; and that the fourth possible combination [-masc,-fem] represents the plural PL; given that there are no gender distinctions in the plural in German, this move is both possible and, it seems, independently motivated. ${ }^{11}$

Consider next the four constraints in (5), which all take the form of relativized FCRs: Each constraint states that a certain set of feature combinations that result from specifying the four features in (4) is incompatible with the presence of certain phonological features, and it does not state this for all elements in the grammar, but only for Case markers (that is why I call the FCRs "relativized"). Thus, according to *VCM, every morpho-syntactic specification in the complement set of the set of categories that are marked [-masc,-obl] (i.e., everything that does not belong to NOM.FEM, ACC.FEM, NOM.PL, or ACC.PL) is incompatible with a vowel as a Case marker (including, of course, /e/). ${ }^{*} \mathrm{DCCM}$ stipulates that categories which are not marked [+fem,-masc] but marked [+gov] are incompatible with a dorsal consonant (i.e., among others, with /R/); in other words: non-feminine ACC items and non-feminine DAT items are incompatible with an /R/ as a Case marker. ${ }^{12}$ Third, ${ }^{*} \mathrm{CORCM}$ states that all categories that bear the features [+masc,+obl,+gov] (i.e., DAT.MASC, DAT.NEUT categories) are incompatible with a coronal Case marker (i.e., among others, with $/ \mathrm{n} /$ and $/ \mathrm{s} /$ ). ${ }^{13}$ And fourth, *SONCM requires categories which are not marked [+masc,-fem,-obl] (i.e., which are not NOM.MASC or ACC.MASC), and which are not marked [-masc] either (i.e., which are not FEM or PL) to remain without a sonorant Case marker (thus, /m/, /n/, /R/, and /e/ are

\footnotetext{
${ }^{11}$ An irrelevant difference to Wiese's $(1996 ; 1999)$ approach is that he calls the primitive feature $[ \pm$ masc] [ \pm standard], and the primitive feature $[ \pm$ fem $][ \pm$ special]. It is worth emphasizing that, independently of the choice of terminology, I do not take these morpho-syntactic gender features to be semantically interpretable in any straightforward way: In some cases, gender and sex may converge; in many cases, they do not.

${ }^{12}$ Given that vowels are [+dorsal] (an assumption often made in feature geometry), additional reference to [+consonantal] is necessary to prevent the constraint from also blocking /e/; see also (10-a) below.

${ }^{13}$ The formulation of $* \mathrm{CORCM}$ and $* \mathrm{DCCM}$ presupposes that the respective articulator features are binary, not privative ([CORONAL], [DORSAL]), but nothing hinges on this in the present context.
} 
blocked in this context). ${ }^{14}$

(5) a. *VCM (Avoid Vocalic Case markers):

$\neg[-$ masc,- obl $] \rightarrow \neg \mathrm{Cm}:[-$ consonantal,+sonorant $]$.

b. *DCCM (Avoid Dorsal Consonantal Case markers):

$\neg[+$ fem,- masc $] \wedge[+$ gov $] \rightarrow \neg \mathrm{Cm}:[+$ dorsal,+consonantal $]$.

c. ${ }^{*} \mathrm{CORCM}$ (Avoid Coronal Case markers):

[+masc, +obl,+gov] $\rightarrow \neg \mathrm{Cm}:[+$ coronal]

$(* / \mathrm{n} /, * / \mathrm{s} /)$

d. *SonCm (Avoid Sonorant Case markers):

$\neg[$ +masc,- fem, - obl $] \wedge \neg[$-masc $] \rightarrow \neg$ Cm:[+sonorant $].$

In $\mathrm{P}_{2}-\mathrm{P}_{5}$, the effects of these four FCRs are illustrated: $\mathrm{x}$ characterizes a morpho-syntactic specification for which the FCR is active. It turns out that more restrictions are imposed on morpho-syntactic specifications that include [+masc] than on those that include [-masc], and similar considerations may hold for [+gov] vs. [-gov] specifications. ${ }^{15}$

$P_{2}: * \mathrm{VCM}: * / \mathrm{e} / \quad P_{3}: * \mathrm{DCCM}: * / \mathrm{R} /$

\begin{tabular}{|l|c|c|c|c|}
\hline & M.SG & N.SG & F.SG & PL \\
\hline \hline NOM & $\mathrm{x}$ & $\mathrm{x}$ & & \\
\hline ACC & $\mathrm{x}$ & $\mathrm{x}$ & & \\
\hline DAT & $\mathrm{x}$ & $\mathrm{x}$ & $\mathrm{x}$ & $\mathrm{x}$ \\
\hline GEN & $\mathrm{x}$ & $\mathrm{x}$ & $\mathrm{x}$ & $\mathrm{x}$ \\
\hline
\end{tabular}

\begin{tabular}{|l|c|c|c|c|}
\hline & M.SG & N.SG & F.SG & PL \\
\hline \hline NOM & & & & \\
\hline ACC & $\mathrm{x}$ & $\mathrm{x}$ & & $\mathrm{x}$ \\
\hline DAT & $\mathrm{x}$ & $\mathrm{x}$ & & $\mathrm{x}$ \\
\hline GEN & & & & \\
\hline
\end{tabular}

Finally, I would like to propose that the sonority hierarchy plays an important role in the determination of Case markers in German. Based on a suggestion in Prince \& Smolensky (1993), I assume that the sonority hierarchy SONHIER is to be viewed as a set of primitive markedness constraints against segments that have a fixed internal ranking, such that constraints against stops invariably outrank constraints against fricatives, which in turn outrank constraints against nasals, etc. What is relevant for present purposes is the following part of SONHIER, which contains constraints against those segments that can possibly qualify as

\footnotetext{
${ }^{14}$ At this point, a remark may be in order concerning the formal nature of these FCRs. The symbols "“" and " $\wedge$ " in (5) both represent a logical "and" (they are distinguished here only so as to improve readability). Then, by DeMorgan's Laws, “ $\neg[+\mathrm{x},-\mathrm{y}]$ ” is equivalent to the disjunction " $[-\mathrm{x}] \vee[+\mathrm{y}]$," at least as long as the absence of a positive feature specification implies the presence of a negative specification of the same feature, and vice versa. There is disagreement concerning the use of disjunctions in constraints of the type that we are interested in here; see, e.g., the opposing views documented in Blevins (1995) and Wunderlich (1997b). The potential problem is that a rich use of disjunction in a constraint may evoke the impression that there is a unified treatment when in fact separate constraints are at work. At least for present purposes, it seems to me that the theory-internal price of disjunctive constraints can be measured by the complexity of the objects that are being disjoined. Thus, in my view, Blevins $(1995,125)$ rightfully criticizes a putative constraint stating that the Case marker $e r$ is used for a determiner if the latter is characterized as either NOM.MASC.SG, DAT.FEM.SG, GEN.FEM.SG, or GEN.PL - which derives the distribution of $e r$ forms in the determiner inflection paradigm with little additional linguistic insight and is virtually indistinguishable from an approach that employs several constraints for this task. However, in the cases in (5), disjunction occurs at the primitive feature level (after application of DeMorgan's Laws). I take this to be innocuous. For the time being, I would like to conclude that there is nothing that prohibits the use of disjunction in constraints as long as the disjoined objects are sufficiently non-complex, and the resulting class is linguistically plausible.

${ }^{15}$ This may or may not suggest deeper asymmetries among these features.
} 


\begin{tabular}{|l|c|c|c|c|}
\hline & M.SG & N.SG & F.SG & PL \\
\hline \hline NOM & & & & \\
\hline ACC & & & & \\
\hline DAT & $\mathrm{x}$ & $\mathrm{x}$ & & \\
\hline GEN & & & & \\
\hline
\end{tabular}

\begin{tabular}{|l|c|c|c|c|}
\hline & M.SG & N.SG & F.SG & PL \\
\hline \hline NOM & & $\mathrm{x}$ & & \\
\hline ACC & & $\mathrm{x}$ & & \\
\hline DAT & $\mathrm{x}$ & $\mathrm{x}$ & & \\
\hline GEN & $\mathrm{x}$ & $\mathrm{x}$ & & \\
\hline
\end{tabular}

the basis for nominal inflection in German. ${ }^{16}$ Crucially, the fixed ranking among the relevant SONHIER subconstraints in (6) is independently motivated on the basis of evidence from, e.g., syllable structure. ${ }^{17}$

(6) SONHIER (Sonority Hierarchy):

$*_{\mathrm{s}} \gg *_{\mathrm{m}} \gg *_{\mathrm{n}} \gg *_{\mathrm{R}} \gg *_{\mathrm{e}}$

As for the ranking of the constraints discussed so far, it is clear that CASE, the sole trigger for Case marking, must outrank both the four FCRs and SONHIER, all of which prohibit the use of segments in Case marking. Furthermore, the FCRs must outrank SONHIER (otherwise, all Case markers would uniformly use /e/); and it will turn out that *SONCM must be lowestranked among the FCRs. The relative ranking of the remaining three FCRs ist not determined by the evidence discussed in this article. Where the precise ranking is not crucial, I will adopt an arbitrary ranking (see Tesar \& Smolensky 2000).

The resulting system works as follows. First, syntactic agreement constraints ensure that that the morpho-syntactic Case and gender/number features $[ \pm \mathrm{obl}],[ \pm \mathrm{gov}],[ \pm$ masc $]$, $[ \pm \mathrm{fem}]$ are copied from the head noun onto all DP and AP specifiers in the minimal residue. Then, a high-ranked CASE demands a Case marker for a given specification of morpho-

\footnotetext{
${ }^{16}$ In what follows, I will have nothing interesting to say about why other segments like, e.g., /t/, /1/, or /a/ cannot be used for Case marking in German. I will simply assume that independent phonological restrictions prohibit the use of segments like /l/ and /a/ in German inflection, and confine the use of /t/ to the verbal domain.

${ }^{17} \mathrm{~A}$ few remarks on (6). First, for the account of determiner inflection given below, it would also be possible to view SONHIER as a single, complex constraint that demands a maximization of sonority according to the (partial) scale [ e $>$ R $>\mathrm{n}>\mathrm{m}>\mathrm{s}$ ] (compare H-NuC in Prince \& Smolensky 1993). However, in section 4 we will encounter evidence for ranking another constraint between two SONHIER subconstraints, which would be impossible under the alternative conception of SONHIER as a single constraint. Second, Prince \& Smolensky (1993) actually tie their versions of the sonority hierarchy to syllable positions, by employing the constraintgenerating mechanism of harmonic alignment of two scales (sonority and position). In contrast, SONHIER in (6) is gained by using only one scale (sonority) in its pure form. I will assume that both types of SONHIER are available in languages - the "pure" version adopted here, as well as the versions obtained by harmonic alignment that are relativized to syllable positions (peak vs. margin). Third, there is one part of SONHIER where the postulation of a fixed ranking may be in need of further justification, viz.: *m $\gg * n$. Evidence for this ranking comes from syllable structure. Sonority must increase in onsets; and one does indeed find [mn] sequences in the non-native German vocabulary (see mnemotechnisch 'mnemotechnic'), whereas there could not possibly be [nm] sequences in German onsets. (Ross 1980, 41 shows that binomial formation in German is partly governed by a constraint that requires sonority in the onsets to decrease - as in Sack und Pack, ruck-zuck vs. *Pack und Sack, *zuck-ruck -, and postulates a reverse hierarchy $\mathrm{m}>\mathrm{n}$ that would translate into a ranking $* \mathrm{n} \gg *^{*} \mathrm{~m}$; however, there is no support for this assumption on the basis of existing idioms, and evidence from newly invented word pairs is not decisive; compare, e.g., nit-mit and mit-nit.) Fourth and finally, whereas the hypothesis that German Case markers maximize sonority is, to the best of my knowledge, new, certain speculations concerning the least consonantal status of /R/ that can be found in Wiese $(1996,341)$ and Zifonun $(2001,41)$ may already point in this direction.
} 
syntactic features at the left edge of the minimal residue of an NP. DPs show up in this position, and consequently, a determiner like dies that is taken from the lexicon as a pure stem must receive a Case marker. Various independent constraints conspire to ensure that Case marking must be a suffix in German, and that only a subset of the phoneme inventory of the language can be used for this purpose. On this basis, the SONHIER subconstraints determine the optimal Case marker, subject to the requirement that higher-ranked FCRs are respected. In other words: Optimization picks out the most sonorous Case marker that is compatible with the FCRs. The Case markers determined this way are simply phonological segments $(/ \mathrm{e} /, / \mathrm{R} /, / \mathrm{n} /, / \mathrm{m} /$, and $/ \mathrm{s} /)$. I would like to contend that ideally, no more should have to be said. On this view, independently motivated phonological constraints of German can be held responsible for the eventual shape of the Case markers. Most importantly, their task is to ensure that the Case marker is usually syllabic, and that a consonantal segment determined by SONHIER and the FCRs cannot end up in the onset. ${ }^{18}$ More specifically, they are responsible for a Schwa realization of /e/, Schwa insertion in the case of consonants, and $\mathrm{R}$ vocalization in syllable codas (see Ito \& Mester 2001 for a recent approach); but they can also be taken to play a role in optional /s/ deletion in NOM.NEUT, ACC.NEUT contexts (see above). ${ }^{19}$ Obviously, then, the present approach is incompatible with the view that German Case markers have an independent existence as morphemes in the lexicon, as assumed in most of the existing literature (rather, it belongs to the class of approaches to inflection that have been called "inferential-realizational"; see Anderson 1992, Stump 2001).

It remains to be shown that each of the five forms in the determiner inflection paradigm $\mathrm{P}_{1}$ emerges as optimal for a given input (I) that contains the lexical item dies, together with a morpho-syntactic specification. ${ }^{20}$ Tableau $\mathrm{T}_{1}$ shows that /e/ is the optimal Case marker (hence, diese is the optimal form) if dies is NOM.FEM, ACC.FEM, NOM.PL, or ACC.PL. There is no FCR that would restrict any of the four feature combinations ([-masc, + fem, - obl, - gov $]$, [-masc, + fem,-obl,+gov], [-masc,-fem,-obl,-gov], and [-masc,-fem,-obl,+gov]. ${ }^{21}$ Consequently, the decision falls to the lower-ranked SONHIER constraints, which select /e/, hence, output $\mathrm{O}_{5}$. The only candidate that improves on SonHIER is $\mathrm{O}_{6}$, without any Case marker, but $\mathrm{O}_{6}$ fatally violates CASE. Thus, /e/ emerges as the unmarked Case marker in German. ${ }^{22}$

\footnotetext{
${ }^{18}$ This presupposes that inflection is syllabic in the unmarked case in German, and that cases of non-syllabic inflection (as in the domain of verbal inflection: lach- $t$ 'laughs') are exceptions for which specific assumptions are needed. The Case marker $/ \mathrm{n} /$ for DAT.PL contexts of nouns (see $\mathrm{P}_{6}$ below) is arguably not expanded into a syllable because it follows a plural marker that is already syllabic.

${ }^{19}$ At least some of these secondary operations can plausibly be modelled by postulating a second, surfaceoriented optimization cycle.

${ }^{20}$ It should be kept in mind that all tableaux that follow typically exhibit only a small part of the syntactic structure that is subject to optimization, which must be either the complete sentence (in standard optimization, cf. Prince \& Smolensky 1993), or at least the minimal NP (in the system of local optimization developed in Heck \& Müller 2000). However, here and in what follows, I will only indicate the minimal amount of structure that is necessary for deciding on the optimal Case marker form - in the case of determiner inflection, this is just the determiner itself.

${ }^{21}$ There is but one exception: [-masc, $\left.-\mathrm{fem},-\mathrm{obl},+\mathrm{gov}\right]$ is restricted by ${ }^{*} \mathrm{DCCM}$. Hence, $\mathrm{O}_{4}$ has a fatal *DCCM violation with this specification, as indicated in the tableau by (*!).

${ }^{22}$ This corresponds to the findings in Blevins (1995) and Wiese (1996; 1999), but is at variance with Bierwisch (1967) and Wunderlich (1997b), where /s/ is considered the unmarked Case marker. As we will see, /s/ turns out to be a highly marked Case marker in the present analysis.
} 
$T_{1}$ : diese

\begin{tabular}{|c|c|c|c|c|c|c|c|c|c|c|}
\hline I: /dies/: NOM.F, ACC.F & CASE & *COR & *DC & $* \mathrm{~V}$ & *SON & \multicolumn{5}{|c|}{ SONHIER } \\
\hline NOM.PL, ACC.PL & & CM & $\mathrm{CM}$ & $\mathrm{CM}$ & $\mathrm{CM}$ & *s & *m & $* \mathrm{n}$ & $*_{\mathrm{R}}$ & $*_{\mathrm{e}}$ \\
\hline$\overline{\mathrm{O}_{1}: \text { dieses }}$ & & & & & & *! & & & & \\
\hline $\mathrm{O}_{2}:$ diesem & & & & & & & $* !$ & & & \\
\hline $\mathrm{O}_{3}$ : diesen & & & & & & & & $* !$ & & \\
\hline $\mathrm{O}_{4}$ : dieser & & & $(* !)$ & & & & & & $*(!)$ & \\
\hline $\mathrm{O}_{5}$ : diese & & & & & & & & & & $*$ \\
\hline $\mathrm{O}_{6}:$ dies & $* !$ & & & & & & & & & \\
\hline
\end{tabular}

Consider next dieser. Tableau $\mathrm{T}_{2}$ illustrates that the Case marker /R/ emerges as optimal for inputs of dies that are NOM.MASC, DAT.FEM, GEN.FEM, or GEN.PL. A Case marker /e/ is blocked in these (and all remaining) contexts by $* \mathrm{VCM}$, but since the other FCRs do not restrict the feature specifications [+masc,-fem,-obl,-gov], [-masc, + fem, + obl, +gov], [masc, + fem, + obl,--gov], and [-masc,-fem, + obl,-gov], the minimization of a violation of the SONHIER constraints implies that /R/ is optimal.

$T_{2}$ : dieser

\begin{tabular}{|l||l|c|c|c|c|c|c|c|c|c|}
\hline $\begin{array}{l}\text { I: /dies/: NOM.M, DAT.F, } \\
\text { GEN.F, GEN.PL }\end{array}$ & CASE & *COR & $* \mathrm{DC}$ & $* \mathrm{~V}$ & $* \mathrm{SON}$ & \multicolumn{5}{|c|}{ SONHIER } \\
\hline \hline $\mathrm{O}_{1}:$ dieses & & & & & & $* !$ & & & & \\
\hline $\mathrm{O}_{2}:$ diesem & & & & & & & $* !$ & & & \\
\hline $\mathrm{O}_{3}$ : diesen & & & & & & & & $* !$ & & \\
\hline $\mathrm{O}_{4}:$ dieser & & & & & & & & & $*$ & \\
\hline $\mathrm{O}_{5}$ : diese & & & & $* !$ & & & & & & $*$ \\
\hline $\mathrm{O}_{6}$ : dies & $* !$ & & & & & & & & & \\
\hline
\end{tabular}

The next best Case marker vis-à-vis SONHIER is $/ \mathrm{n} /$. As shown in tableau $\mathrm{T}_{3}$, diesen is optimal, blocking less sonorous $/ \mathrm{m} /$ and $/ \mathrm{s} /$, in exactly those contexts where $* \mathrm{VCM}$ and *DCCM prohibit/e/ and /R/ as Case markers and the other FCRs are vacuously fulfilled, viz., in the case of ACC.MASC ([+masc, - fem,,- obl, +gov $])$ and DAT.PL ([-masc, - fem, + obl, +gov $])$. $T_{3}:$ diesen

\begin{tabular}{|c|c|c|c|c|c|c|c|c|c|c|}
\hline I: /dies/: ACC.M, & CASE & $* \mathrm{COR}$ & $* \mathrm{DC}$ & $* \mathrm{~V}$ & $* \mathrm{SON}$ & \multicolumn{5}{|c|}{ SONHIER } \\
\hline DAT.PL & & $\mathrm{CM}$ & $\mathrm{CM}$ & $\mathrm{CM}$ & $\mathrm{CM}$ & $*_{\mathrm{S}}$ & $*_{\mathrm{m}}$ & $* \mathrm{n}$ & $*_{\mathrm{R}}$ & $*_{\mathrm{e}}$ \\
\hline $\mathrm{O}_{1}$ : dieses & & & & & & $* !$ & & & & \\
\hline $\mathrm{O}_{2}:$ diesem & & & & & & & $* !$ & & & \\
\hline $\mathrm{O}_{3}:$ diesen & & & & & & & & $*$ & & \\
\hline $\mathrm{O}_{4}:$ dieser & & & $* !$ & & & & & & $*$ & \\
\hline $\mathrm{O}_{5}:$ diese & & & & $* !$ & & & & & & $*$ \\
\hline $\mathrm{O}_{6}:$ dies & $* !$ & & & & & & & & & \\
\hline
\end{tabular}

With diesem, we move into marked domains of determiner inflection, where the sonority hierarchy does not predict the outcome anymore. The form diesem is classified as optimal in DAT.MASC and DAT.NEUT contexts ([+masc,-fem,+obl,+gov], [+masc, + fem, + obl,+gov]); see tableau $\mathrm{T}_{4}$. A Case marker $/ \mathrm{m} /$ violates the FCR $*$ SoNCM here, but it is optimal nevertheless because all other potential Case markers violate higher-ranked constraints. 


\begin{tabular}{|c|c|c|c|c|c|c|c|c|c|c|}
\hline I: /dies/: DAT.M, & CASE & ${ }^{*}$ COR & *DC & $* \mathrm{~V}$ & *SON & \multicolumn{5}{|c|}{ SONHIER } \\
\hline DAT.N & & $\mathrm{CM}$ & $\mathrm{CM}$ & $\mathrm{CM}$ & $\mathrm{CM}$ & $*_{\mathrm{s}}$ & $* \mathrm{~m}$ & $*_{\mathrm{n}}$ & $*_{\mathrm{R}}$ & $*_{\mathrm{e}}$ \\
\hline$\overline{\mathrm{O}_{1}: \text { dieses }}$ & & *! & & & & * & & & & \\
\hline $\mathrm{O}_{2}:$ diesem & & & & & * & & $*$ & & & \\
\hline $\mathrm{O}_{3}:$ diesen & & $* !$ & & & * & & & $*$ & & \\
\hline $\mathrm{O}_{4}$ : dieser & & & $* !$ & & * & & & & $*$ & \\
\hline $\mathrm{O}_{5}$ : diese & & & & *! & * & & & & & $*$ \\
\hline $\mathrm{O}_{6}: \operatorname{dies}$ & $* !$ & & & & & & & & & \\
\hline
\end{tabular}

The remaining form dieses is optimal for the input specifications NOM.NEUT, ACC.NEUT, GEN.MASC., and GEN.NEUT ([+masc,+fem,-obl,-gov], [+masc,+fem,-obl,+gov], [+masc,fem,+obl,-gov], [+masc,+fem,+obl,-gov]). The reason is that /s/ is the only Case marker that does not violate $*$ SONCM. ${ }^{23}$

$T_{5}$ : dieses

\begin{tabular}{|c|c|c|c|c|c|c|c|c|c|c|}
\hline I: /dies/: NOM.N, ACC.N, & CASE & ${ }^{*} \mathrm{COR}$ & *DC & $* \mathrm{~V}$ & *SON & \multicolumn{5}{|c|}{ SONHIER } \\
\hline GEN.M, GEN.N & & $\mathrm{CM}$ & $\mathrm{CM}$ & $\mathrm{CM}$ & $\mathrm{CM}$ & $*_{\mathrm{s}}$ & *m & $* \mathrm{n}$ & $*_{\mathrm{R}}$ & $*_{\mathrm{e}}$ \\
\hline $\mathrm{O}_{1}$ : dieses & & & & & & * & & & & \\
\hline $\mathrm{O}_{2}:$ diesem & & & & & $* !$ & & $*$ & & & \\
\hline $\mathrm{O}_{3}$ : diesen & & & & & *! & & & $*$ & & \\
\hline $\mathrm{O}_{4}$ : dieser & & & $(* !)$ & & $*(!)$ & & & & * & \\
\hline $\mathrm{O}_{5}:$ diese & & & & $* !$ & * & & & & & * \\
\hline $\mathrm{O}_{6}: \operatorname{dies}$ & $* !$ & & & & & & & & & \\
\hline
\end{tabular}

Concluding so far, all instances of syncretism with demonstrative determiner inflection have been shown to be systematic, in the sense that the reason for choosing homophonous forms for (sometimes radically) different feature specifications is identical in each of the five cases. The analysis given for dies also covers other determiners, including, with minimal modification, the definite article (der, die, das, etc. 'the'). In this case, the determination of Case markers proceeds exactly as shown in $\mathrm{T}_{1}-\mathrm{T}_{5}$. The only thing that differs is that vowel changes occur in the stem, but, as Wiese (2001) has shown, these are completely predictable and thus do not threaten to undermine the present proposal: Assuming that the underlying form is uniformly $d e$, /e/ is realized as [a] (in Standard German, but interestingly not in certain colloquial and regional varieties) in the context [+masc, $+\mathrm{fem},-\mathrm{obl}]$, as [i:] in /e/-/e/ sequences, and its length depends on the status of the following consonant as voiced or voiceless.

Finally, the analysis must be extended to pronominal uses of determiners. Note that CASE only requires a Case marker at the left edge of an NP; therefore, it will not suffice to assume that determiners like dies and de can be free-standing DPs without NP-embedding. Various solutions to this technical problem are conceivable. For the sake of concreteness, I will assume that a determiner that is used as a pronoun also heads a DP in SpecN, where N is phonologically empty. Such an assumption is independently motivated for semantic reasons (to provide a variable that the determiner can quantify over), and straightforwardly opens up

\footnotetext{
${ }^{23}$ Note that whereas dieser violates $* \mathrm{SONCM}$ throughout in this context, it also (fatally) violates $* \mathrm{DCCM}$ with an ACC.NEUT specification; hence the use of brackets in $\mathrm{O}_{4}$.
} 
the possiblity of modification by APs or relative clauses below the pronoun. Thus, the core domain of determiner inflection is accounted for. I will now turn to the other part of the NP that CASE requires a Case marker for: $\mathrm{N}$.

\section{Noun inflection}

German noun inflection as such is fairly complex. However, if we restrict our attention to genuine Case marking and are willing to abstract away from minor declension types and archaisms, the picture that arises is actually quite simple. Many complications with noun inflection result from the intricacies of plural marking. In contrast to what is the case with determiners (and adjectives, see below), plural marking on German nouns is agglutinative, in the sense that separate "blocks" (see Anderson 1992, Stump 2001) can be identified for plural marking and Case marking. Plural marking is not triggered by CASE; and as a matter of fact, the present analysis is completely neutral as to whether plural marking occurs in the syntax or somewhere else. To simplify the following discussion, I will assume the latter: Plural markers (including Umlaut) are already attached to noun stems in the syntactic input. ${ }^{24}$

In addition to plural marking, I will ignore the peculiar mixed inflection patterns with a small set of nouns like Herz ('heart') and Funke ('spark'), which are highly irregular and will probably disappear soon (see Wurzel 1990, Gallmann 1996). Similarly, I will not consider the marker /e/ that shows up in DAT.MASC and DAT.NEUT contexts on nouns (as in aus hartem Holze 'of solid wood'). This archaic marker can only occur on a small subset of MASC./NEUT nouns in the first place (restrictions include a strong tendency towards monosyllabicity and a confinement to the native vocabulary, among several others; see Gelhaus 1998, 225); it typically occurs in idiomatic expressions; it is systematically abandoned by most younger speakers; and it seems fair to say that it cannot be acquired anymore during language acquisition without conscious effort.

An arguably less obvious omission concerns the putative GEN Case marker/s/ on proper names. This marker is largely confined to a specific designated position, viz., SpecN (as in Karls Buch 'Karl's book'); unlike GEN markers with other types of noun, it can hardly occur in an argument position of $\mathrm{V}$ or $\mathrm{P}$ (see ?*Man erinnerte sich Karls 'One remembered $\operatorname{Karl}_{\text {gen }}$, , ?*unterhalb Karls 'below $\mathrm{Karl}_{\text {gen }}$ '), or in a complement position of $\mathrm{N}$ (see ?*das Buch Karls 'the book Karl ${ }_{g e n}$ '). Moreover, /s/ on proper names in SpecN can never trigger Schwa insertion, unlike the regular/s/ Case marker to be discussed immediately. For these reasons, I conclude that the /s/ marker on proper names is best not analyzed as a Case marker whose presence is forced by CASE, but as a possessive (-like) marker that is demanded by some other constraint which falls outside the scope of the present article.

Finally, for now I will abstract away from $/ \mathrm{n} /$ as a marker for ACC, DAT, and GEN in the so-called weak masculine declension. A discussion of this type of inflection is deferred until subsection 4.5 (and the conclusion will be that this $/ \mathrm{n} /$ is not a Case marker either). Given

\footnotetext{
${ }^{24}$ That said, plural marking in German, while highly idiosyncratic at first sight, turns out to be principled to a large degree upon closer inspection. Moreover, optimality-theoretic analyses have recently been developed that can be reconciled with the present approach without too much ado; see Elgersma \& Houseman (1999), Wegener (1999), Wunderlich (1999), and, for the interesting case of subtractive plurals in German dialects, Golston \& Wiese (1996).
} 
these premisses, there are only two Case markers left for nouns. First, /s/ is used as a Case marker for GEN.MASC and GEN.NEUT. Second, $/ \mathrm{n} /$ is used as a Case marker for DAT.PL. In all other contexts, German nouns do not have any Case marker whatsoever. We can thus devise a reduced paradigm $\mathrm{P}_{6}$ for noun inflection.

$P_{6}:$ Noun inflection

\begin{tabular}{|l|c|c|c|c|}
\hline & M.SG & N.SG & F.SG & PL \\
\hline \hline NOM & & & & \\
\hline ACC & & & & \\
\hline DAT & & & & $\mathrm{n}$ \\
\hline GEN & (e)s & (e)s & & \\
\hline
\end{tabular}

To account for this state of affairs, an additional FCR $* \mathrm{NCM}$ is needed that blocks Case marking on $\mathrm{N}$ (represented here as $[+\mathrm{N},-\mathrm{V}]$ ) in all contexts except for GEN.MASC, GEN.NEUT, and DAT.PL; in contrast to all other FCRs discussed so far, *NCM must outrank CASE. $^{25}$

(7) * NCM (Avoid Case markers on $\mathrm{N})$ :

$[+\mathrm{N},-\mathrm{V}] \wedge \neg[+$ masc,+ obl, - gov $] \wedge \neg[$-masc, - fem,, obl, + gov $] \rightarrow \neg \mathrm{Cm}$

Tableau $\mathrm{T}_{6}$ illustrates the effect of $* \mathrm{NCM}$ for an arbitrarily chosen context in which this constraint is active, viz., ACC.NEUT ([+masc, + fem, - obl, +gov]). All outputs with a Case marker fatally violate $\mathrm{CASE}$; hence, $\mathrm{O}_{6}$, which does not have a Case marker, is optimal. $T_{6}:$ Buch

\begin{tabular}{|c|c|c|c|c|c|c|c|c|c|c|c|}
\hline I: /Buch/: & $* \mathrm{~N}$ & CASE & $* \mathrm{COR}$ & $* \mathrm{DC}$ & $* \mathrm{~V}$ & *SON & \multicolumn{5}{|c|}{ SONHIER } \\
\hline ACC.N & $\mathrm{CM}$ & & $\mathrm{CM}$ & $\mathrm{CM}$ & $\mathrm{CM}$ & $\mathrm{CM}$ & $*_{\mathrm{s}}$ & $* \mathrm{~m}$ & $* \mathrm{n}$ & $*_{\mathrm{R}}$ & $*_{\mathrm{e}}$ \\
\hline $\mathrm{O}_{1}$ : Buches & $* !$ & & & & & & $*$ & & & & \\
\hline $\mathrm{O}_{2}$ : Buchem & $* !$ & & & & & * & & * & & & \\
\hline $\mathrm{O}_{3}$ : Buchen & *! & & & & & * & & & $*$ & & \\
\hline $\mathrm{O}_{4}:$ Bucher & $* !$ & & & & & * & & & & $*$ & \\
\hline $\mathrm{O}_{5}$ : Buche & $* !$ & & & & $*$ & $*$ & & & & & * \\
\hline $\mathrm{O}_{6}: \mathrm{Buch}$ & & * & & & & & & & & & \\
\hline
\end{tabular}

A more interesting case is provided by contexts in which a Case marker does not violate $* \mathrm{NCM}$, and CASE is consequently not violable by an optimal output, e.g., GEN.NEUT ([+masc, + fem, + obl,-gov $])$. As shown in $\mathrm{T}_{5}$, the optimal Case marker for this context is /s/ in the case of determiners. Indeed, no more needs to be said for nouns; $\mathrm{T}_{7}$ parallels $\mathrm{T}_{5}$ in all relevant respects.

Similar considerations apply to DAT.PL contexts. As shown in $\mathrm{T}_{3}$, the optimal Case marker for a [-masc,-fem,+obl,-gov] specification is /n/, which best satisfies SONHIER among the phonological segments that respect the higher-ranked FCRs. Consequently, /n/ also emerges as the optimal Case marker in tableau $\mathrm{T}_{8}$, which is identical to $\mathrm{T}_{3}{ }^{26}$

\footnotetext{
$25 * \mathrm{NCM}$ may ultimately follow as a theorem from the interaction of several simpler constraints.

${ }^{26}$ Recall that, to simplify the exposition, plural marking is assumed to be part of the syntactic input. Nothing would preclude a simultaneous syntactic plural determination on the basis of a singular stem Buch, though, assuming that the feature difference between $[+$ masc,+ fem $]$ in the singular and $[-$ masc,,- fem $]$ in the plural
} 
$T_{7}$ : Buches

\begin{tabular}{|l||c|c|c|c|c|c|c|c|c|c|c|}
\hline I: /Buch/: & $* \mathrm{~N}$ & CASE & $* \mathrm{COR}$ & $* \mathrm{DC}$ & $* \mathrm{~V}$ & $* \mathrm{SON}$ & \multicolumn{5}{|c|}{ SONHIER } \\
GEN.N & $\mathrm{CM}$ & & $\mathrm{CM}$ & $\mathrm{CM}$ & $\mathrm{CM}$ & $\mathrm{CM}$ & $* \mathrm{~s}$ & $* \mathrm{~m}$ & $* \mathrm{n}$ & $* \mathrm{R}$ & $* \mathrm{e}$ \\
\hline \hline $\mathrm{O}_{1}:$ Buches & & & & & & & $*$ & & & & \\
\hline $\mathrm{O}_{2}:$ Buchem & & & & & & $* !$ & & $*$ & & & \\
\hline $\mathrm{O}_{3}:$ Buchen & & & & & & $* !$ & & & $*$ & & \\
\hline $\mathrm{O}_{4}:$ Bucher & & & & & & $* !$ & & & & $*$ & \\
\hline $\mathrm{O}_{5}:$ Buche & & & & & $* !$ & $*$ & & & & & $*$ \\
\hline $\mathrm{O}_{6}:$ Buch & & $* !$ & & & & & & & & & \\
\hline
\end{tabular}

$T_{8}:$ Büchern

\begin{tabular}{|c|c|c|c|c|c|c|c|c|c|c|c|}
\hline I: /Bücher/: & $* \mathrm{~N}$ & CASE & $* \mathrm{COR}$ & $* \mathrm{DC}$ & $* \mathrm{~V}$ & $* \mathrm{SON}$ & \multicolumn{5}{|c|}{ SONHIER } \\
\hline DAT.PL & $\mathrm{CM}$ & & $\mathrm{CM}$ & $\mathrm{CM}$ & $\mathrm{CM}$ & $\mathrm{CM}$ & $*_{\mathrm{s}}$ & $* \mathrm{~m}$ & $* n$ & $*_{\mathrm{R}}$ & $*_{\mathrm{e}}$ \\
\hline $\mathrm{O}_{1}$ : Büchers & & & & & & & $* !$ & & & & \\
\hline $\mathrm{O}_{2}$ : Bücherm & & & & & & & & $* !$ & & & \\
\hline $\mathrm{O}_{3}:$ Büchern & & & & & & & & & $*$ & & \\
\hline $\mathrm{O}_{4}:$ Bücherer & & & & $* !$ & & & & & & $*$ & \\
\hline $\mathrm{O}_{5}:$ Büchere & & & & & $* !$ & & & & & & * \\
\hline $\mathrm{O}_{6}:$ Bücher & & $* !$ & & & & & & & & & \\
\hline
\end{tabular}

Thus, it turns out that noun inflection in German follows exactly the constraints that regulate determiner inflection, once the intervention of a high-ranked constraint blocking Case markers on nouns in most contexts is taken into account. With Case marking of the prototypical edges of the minimal residue of NP (viz., DP and N) accounted for, I will now turn to adjective inflection in $\mathrm{SpecN}$, which is often (but not always) a non-edge phenomenon.

\section{Adjective inflection}

Usually, three types of adjective inflection are distinguished: weak, strong, and mixed inflection. I will address these cases in turn.

\subsection{Weak inflection}

The paradigm $\mathrm{P}_{7}$ for weak adjective inflection only contains two distinct markers, viz., /e/ and $/ \mathrm{n} /$, realized as Schwa $e$ and $e n$, respectively.

As a first step towards an account, two related observations can be made. First, weak adjective inflection is parasitic on Case marking in the sense that it can never occur without a Case marker being present. (8) illustrates weak adjective inflection in NOM (a), ACC (b), DAT

(which must be assumed because the singular gender information is partly relevant for determining the optimal plural marker; see Hoberg 2001 and literature cited there) can be properly represented; however, such an enterprise would be problematic in an approach like minimalist morphology. Note furthermore that, of the four German plural markers $/ \mathrm{e} /, / \mathrm{r} /, / \mathrm{n} /$, and $/ \mathrm{s} /$, only the former two permit the Case marker $/ \mathrm{n} /$ in DAT contexts. I take this to result from the intervention of phonological constraints that force the deletion (i.e., non-parsing) of an otherwise expected /n/ in this environment (see Opas*n 'grandfathers ${ }_{\text {dat }}$ ', Frauen*en 'women ${ }_{\text {dat }}$ '); see Eisenberg (1998, 161), Neef (1998, 236), Wurzel (1998, 234), and Wunderlich (1999, 4), among others, on what the pertinent phonological constraints might look like. 
$P_{7}:$ Weak adjective inflection

\begin{tabular}{|l|c|c|c|c|}
\hline gut & M.SG & N.SG & F.SG & PL \\
\hline \hline NOM & e & e & e & en \\
\hline ACC & en & e & e & en \\
\hline DAT & en & en & en & en \\
\hline GEN & en & en & en & en \\
\hline
\end{tabular}

(c), and GEN (d) contexts, for MASC (Tee 'tea'), NEUT (Bier 'beer'), FEM (Milch 'milk'), and PL (Gläser 'glasses') nouns.

(8) NOM dieser gute Tee, dieses gute Bier, diese gute Milch, diese guten Gläser ACC diesen guten Tee, dieses gute Bier, diese gute Milch, diese guten Gläser DAT diesem guten Tee, diesem guten Bier, dieser guten Milch, diesen guten Gläsern GEN dieses guten Tees, dieses guten Bieres, dieser guten Milch, dieser guten Gläser 'this good tee (MASC), this good beer (NEUT), this good milk (FEM), these good glasses (PL)'

Second, since weak adjective inflection is contextually triggered by a Case marker which is in turn required by CASE, it is clear that this type of inflection cannot directly be triggered by CASE itself: The left edge is already Case marked, and even if the right edge $(\mathrm{N})$ is not Case marked, a Case marker on an adjective in SpecN will not improve an output's behaviour towards CASE (see above). I would like to suggest that weak adjective inflection should not be viewed as an instance of Case marking at all; rather, what is involved here is an agreement effect, triggered by the constraint AGR in (9).

(9) AGR (Agreement):

An adjective that shares a minimal residue with a Case marker on another type of head requires an agreement marker.

An adjective that is preceded by a determiner within the same NP requires an agreement marker if the determiner has a Case marker. AGR can only become relevant if CASE forces the presence of a Case marker in an output; and if it is active, it requires an agreement marker. Thus, the weak adjective endings are agreement markers. ${ }^{27}$ A background assumption that I adopt here is that nothing can act as a Case marker and as an agreement marker at the same time. This may be an inviolable constraint belonging to the Gen component of an optimality-theoretic grammar, or a high-ranked constraint that cannot be violated by a wellformed output in German.

So far, there are no special restrictions on the form of the agreement marker (the five FCRs introduced above only hold for Case markers). Hence, if nothing else is said, we should expect SONHIER to uniformly predict an /e/, which is not quite correct. However, given the two constraints in (10), the weak adjective paradigm can be derived.

(10) a. *DAm (Avoid Dorsal Agreement markers):

$$
\neg[-\mathrm{Pl},-\mathrm{obl}] \rightarrow \neg \mathrm{Am:}[+ \text { dorsal }] \text {. }
$$

b. GMCOR (GM Correspondence):

\footnotetext{
${ }^{27}$ More generally, the distinction between Case markers and agreement markers in the present approach parallels the standard distinction between strong and weak inflection. These latter notions play no independent role in the present analysis.
} 
$[+$ masc, + gov $]$ items in the same minimal residue have identical markers.

*DAM is a FCR relativized with respect to agreement markers. It states that all categories which are not $[-\mathrm{obl}]$ and $[-\mathrm{Pl}]$ are incompatible with a dorsal agreement marker, i.e., with /R/ and $/ \mathrm{e} /{ }^{28} \mathrm{GMCOR}$ is a constraint that is of a different type from those discussed so far (the marker triggers CASE and AGR, the FCRs, and SONHIER). This constraint is reminiscent of correspondence constraints in optimality theory because it requires two categories $\alpha$ and $\beta$ to have identical markers. ${ }^{29}$ The three new constraints are integrated into the overall ranking as follows. AGR outranks CASE (although this will only become relevant in subsection 4.2 below). *DAM is ranked higher than SONHIER. Finally, GMCOR must intervene in the domain of the SONHIER constraints: It is ranked lower than ${ }^{*} \mathrm{~m}$, but ranked higher than $* \mathrm{n} .{ }^{30}$

The following tableaux give illustrative examples of how weak adjective declension arises, i.e., how agreement markers are distributed on adjectives. Since an agreement marker presupposes a Case marker in the same minimal residue, more structure than before must be taken into account. For present purposes, it suffices to consider the adjective together with a preceding determiner (most of the optimal outputs in what follows will have to violate CASE once, but these violations incurred by Case-less Ns can safely be ignored throughout). Assuming, as before, that there are five a priori conceivable marker forms plus one form without a marker, and two relevant NP-internal categories on which markers may occur, this gives us thirty-six relevant outputs to consider. Of these, I will generally confine myself to those candidates that have a chance to become optimal. Let us begin with a NOM.FEM ([-masc, + fem,-obl,-gov]) specification on both D and A. ${ }^{31}$ Tableau $\mathrm{T}_{9}$ shows why /e/ is optimal both as a Case marker on dies, and as an agreement marker on gut in this context. ${ }^{32}$ Outputs like $\mathrm{O}_{45}$ that do not have /e/ as the Case marker for the determiner are ill formed for the reasons discussed above (see $\mathrm{T}_{1}$ ). Among the outputs $\mathrm{O}_{51}-\mathrm{O}_{56}$ that have a Case marker

\footnotetext{
${ }^{28}$ Note that $[-\mathrm{Pl}]$ is an abbreviation for $\neg[-\mathrm{masc},-\mathrm{fem}]$. In this case, a straightforward disjunctive formulation of the constraint might arguably be easier to grasp: *DAM prohibits dorsal agreement markers on categories that are plural or oblique.

${ }^{29}$ However, it is worth pointing out that GMCOR does not belong to any of the subclasses of correspondence constraints envisaged in McCarthy \& Prince (1995). It is not an input/output correspondence constraint because (Case or agreement) markers are not yet part of the input; and it is not an output/output correspondence constraint because GMCOR requires only those markers to be identical in form that occur within the same output, not on some other output that has independently been optimized. The input/output vs. output/output correspondence distinction can be viewed as similar to the distinction between rules of exponence and rules of referral (see Stump 2001). Both output/output constraints and rules of referral may initially look attractive in inflectional morphology. However, they are extremely powerful means that the present analysis does not resort to (see also Wunderlich 1996, 107-112).

${ }^{30}$ In fact, $*$ DAM only has to be ranked higher than $*$ n; thus, it could (but, unlike, GMCOR, does not have to) have a ranking between $* m$ and $* n$.

${ }^{31}$ Recall that I assume that it follows from syntactic agreement constraints that these features must be identical on DP and AP specifiers of N. These constraints are not to be confused with the constraint AGR introduced above: They govern the distribution of morpho-syntactic features in minimal residues; AGR (like CASE) is exclusively concerned with the morphological realization of a given morpho-syntactic specification.

${ }^{32}$ Two remarks on notation. First, I systematically leave out $*$ NCM in the tableaux of this subsection, and I group the remaining four FCRs for Case markers together under the label * XCM. Second, the output candidates are numbered according to a self-explanatory system in which " 1 " stands for /s/, " 2 " for /m/, " 3 " for /n/, " 4 " for $/ \mathrm{r} /$, " 5 " for /e/, and " 6 " for the absence of a (Case or agreement) marker.
} 
/e/ on dies, the SONHIER constraints straightforwardly predict $\mathrm{O}_{55}$ to be optimal. Note that whereas $\mathrm{O}_{56}$ fatally violates AGR, $\mathrm{O}_{66}$ does not: AGR does not per se require an agreement marker on an adjective below a determiner; it does so only if the determiner is Case marked. $T_{9}$ : diese gute (Milch)

\begin{tabular}{|c||c|c|c|c|c|c|c|c|c|c|}
\hline $\begin{array}{l}\text { I: /dies, gut/: } \\
\text { NOM.F }\end{array}$ & AGR & CASE & $\begin{array}{c}* \mathrm{D} \\
\text { AM }\end{array}$ & $\begin{array}{c}* \mathrm{X} \\
\mathrm{CM}\end{array}$ & $* \mathrm{~s}$ & $* \mathrm{~m}$ & $\begin{array}{c}\mathrm{GM} \\
\mathrm{COR}\end{array}$ & $* \mathrm{n}$ & $*_{\mathrm{R}}$ & ${ }^{*} \mathrm{e}$ \\
\hline \hline $\mathrm{O}_{45}:$ dieser gute & & & & & & & & & $* !$ & $*$ \\
\hline $\mathrm{O}_{51}:$ diese gutes & & & & & $* !$ & & & & & $*$ \\
\hline $\mathrm{O}_{52}:$ diese gutem & & & & & & $* !$ & & & & $*$ \\
\hline $\mathrm{O}_{53}:$ diese guten & & & & & & & & $* !$ & & $*$ \\
\hline $\mathrm{O}_{54}:$ diese guter & & & & & & & & & $* !$ & $*$ \\
\hline $\mathrm{O}_{55}:$ diese gute & & & & & & & & & & $* *$ \\
\hline $\mathrm{O}_{56}:$ diese gut & $* !$ & & & & & & & & & $*$ \\
\hline $\mathrm{O}_{66}:$ dies gut & & $* !$ & & & & & & & & \\
\hline
\end{tabular}

Next consider an input with a GEN.MASC ([+masc,-fem,+obl,-gov]) specification. Here, a Case marker $/ \mathrm{s} /$ and an agreement marker $/ \mathrm{n} /$ emerge as optimal; see tableau $\mathrm{T}_{10}$. Any output without /s/ as the Case marker will invariably be suboptimal; see $\mathrm{T}_{5}$. This time, however, /e/ is blocked as an agreement marker because of $* \mathrm{DAM}$, which prohibits dorsals in contexts that include GEN.MASC (see $\mathrm{O}_{15}$ ). Since the same goes for $/ \mathrm{R} /\left(\right.$ see $\left.\mathrm{O}_{14}\right), \mathrm{n} / \mathrm{is}$ chosen as the optimal agreement marker by the SONHIER constraints (see $\mathrm{O}_{13}$ vs. $\mathrm{O}_{12}, \mathrm{O}_{11}$ ).

$T_{10}$ : dieses guten (Tees)

\begin{tabular}{|l||c|c|c|c|c|c|c|c|c|c|}
\hline $\begin{array}{l}\text { I: /dies, gut/: } \\
\text { GEN.M }\end{array}$ & AGR & CASE & $\begin{array}{c}* \mathrm{D} \\
\text { AM }\end{array}$ & $\begin{array}{c}* \mathrm{X} \\
\mathrm{CM}\end{array}$ & $* \mathrm{~s}$ & $* \mathrm{~m}$ & $\begin{array}{c}\text { GM } \\
\text { COR }\end{array}$ & $* \mathrm{n}$ & $* \mathrm{R}$ & $* \mathrm{e}$ \\
\hline \hline $\mathrm{O}_{11}:$ dieses gutes & & & & & $* * !$ & & & & & \\
\hline $\mathrm{O}_{12}:$ dieses gutem & & & & & $*$ & $* !$ & & & & \\
\hline $\mathrm{O}_{13}:$ dieses guten & & & & & $*$ & & & $*$ & & \\
\hline $\mathrm{O}_{14}:$ dieses guter & & & $* !$ & & $*$ & & & & $*$ & \\
\hline $\mathrm{O}_{15}:$ dieses gute & & & $* !$ & & $*$ & & & & & $*$ \\
\hline $\mathrm{O}_{16}:$ dieses gut & $* !$ & & & & $*$ & & & & & \\
\hline
\end{tabular}

So far, GMCOR has not been active in competitions. This changes when [+masc,+gov] specifications are considered. In particular, consider the competition in ACC.MASC ([+masc,-fem,-obl,+gov]) contexts, which is illustrated in tableau $\mathrm{T}_{11}$. Without GMCor, we would expect $\mathrm{O}_{35}$ to be optimal, because of the ranking *n $\gg *$ e in SONHIER (note that *DAM does not block $\mathrm{O}_{34}, \mathrm{O}_{35}$ here). But GMCOR requires marker identity for dies and gut (which $\mathrm{O}_{34}$ and $\mathrm{O}_{35}$ do not exhibit), and since GMCOR outranks *n, $\mathrm{O}_{33}$, which has identical markers, has a better constraint profile and is correctly classified as optimal. Other candidates (like $\mathrm{O}_{44}, \mathrm{O}_{55}$ ) may also respect GMCoR, but they fatally violate higher-ranked *XCM constraints.

Whereas tableau $\mathrm{T}_{11}$ has shown that the ranking GMCOR $\gg * n$ is important, tableau $\mathrm{T}_{12}$ shows that the ranking $* \mathrm{~m} \gg \mathrm{GMCOR}$ is also indispensable. In DAT.MASC ([+masc,fem,+obl,+gov]) contexts, $\mathrm{O}_{23}$ (without matching Case markers) blocks $\mathrm{O}_{22}$ (with $/ \mathrm{m} / \mathrm{as}$ both a Case and an agreement marker). The reason is that GMCOR has to be fulfilled only if no higher-ranked SONHIER constraint is violated; but *m, by assumption, is ranked higher. 
$T_{11}$ : diesen guten (Tee)

\begin{tabular}{|c||c|c|c|c|c|c|c|c|c|c|}
\hline $\begin{array}{l}\text { I: /dies, gut/: } \\
\text { ACC.M }\end{array}$ & AGR & CASE & $\begin{array}{c}* \mathrm{D} \\
\text { AM }\end{array}$ & $* \mathrm{X}$ & $* \mathrm{~s}$ & $* \mathrm{~m}$ & $\begin{array}{c}\mathrm{GM} \\
\mathrm{CM}\end{array}$ & $* \mathrm{n}$ & $* \mathrm{R}$ & $* \mathrm{e}$ \\
\hline \hline $\mathrm{O}_{31}:$ diesen gutes & & & & & $* !$ & & $*$ & $*$ & & \\
\hline $\mathrm{O}_{32}:$ diesen gutem & & & & & & $* !$ & $*$ & $*$ & & \\
\hline $\mathrm{O}_{33}:$ diesen guten & & & & & & & & $* *$ & & \\
\hline $\mathrm{O}_{34}:$ diesen guter & & & & & & & $* !$ & $*$ & $*$ & \\
\hline $\mathrm{O}_{35}:$ diesen gute & & & & & & & $* !$ & $*$ & & $*$ \\
\hline $\mathrm{O}_{36}:$ diesen gut & $* !$ & & & & & & $*$ & $*$ & & \\
\hline $\mathrm{O}_{44}:$ dieser guter & & & & $* !$ & & & & & $* *$ & \\
\hline $\mathrm{O}_{55}:$ diese gute & & & & $* !$ & & & & & & $* *$ \\
\hline
\end{tabular}

There are other outputs (like $\mathrm{O}_{33}, \mathrm{O}_{44}$, and $\mathrm{O}_{55}$ ) that satisfy GMCOR without violating *m, but these fatally violate higher-ranked constraints in *XCM (in some cases, also *DAM). ${ }^{33}$

$T_{12}$ : diesem guten (Tee)

\begin{tabular}{|l||c|c|c|c|c|c|c|c|c|c|}
\hline $\begin{array}{l}\text { I: /dies, gut/: } \\
\text { DAT.M, DAT.N }\end{array}$ & AGR & CASE & $\begin{array}{c}* \mathrm{D} \\
\mathrm{AM}\end{array}$ & $* \mathrm{X}$ & $* \mathrm{~s}$ & $* \mathrm{~m}$ & $\mathrm{GM}$ & $* \mathrm{n}$ & $* \mathrm{R}$ & $* \mathrm{e}$ \\
\hline \hline $\mathrm{O}_{21}:$ diesem gutes & & & & $*$ & $* !$ & $*$ & $*$ & & & \\
\hline $\mathrm{O}_{22}:$ diesem gutem & & & & $*$ & & $* * !$ & & & & \\
\hline $\mathrm{O}_{23}:$ diesem guten & & & & $*$ & & $*$ & $*$ & $*$ & & \\
\hline $\mathrm{O}_{24}:$ diesem guter & & & $* !$ & $*$ & & $*$ & $*$ & & $*$ & \\
\hline $\mathrm{O}_{25}:$ diesem gute & & & $* !$ & $*$ & & $*$ & $*$ & & & $*$ \\
\hline $\mathrm{O}_{26}:$ diesem gut & $* !$ & & & $*$ & & $*$ & $*$ & & & \\
\hline $\mathrm{O}_{33}:$ diesen guten & & & & $* * !$ & & & & $* *$ & & \\
\hline $\mathrm{O}_{44}:$ dieser guter & & & $* !$ & $* *$ & & & & & $* *$ & \\
\hline $\mathrm{O}_{55}:$ diese gute & & & $* !$ & $* *$ & & & & & & $* *$ \\
\hline
\end{tabular}

As a final example of how weak adjective agreement is created by syntactic optimization, consider ACC.NEUT ([+masc, + fem,-obl,+gov]) contexts; see tableau $\mathrm{T}_{13}$. ${ }^{*} \mathrm{DAM}$ does not discriminate between the competitors here. Outputs that satisfy GMCOR fatally violate either *XCM constraints that regulate the optimal Case marker shape ( $\mathrm{Xee}^{\mathrm{O}} \mathrm{O}_{22}, \mathrm{O}_{33}, \mathrm{O}_{44}$, and $\left.\mathrm{O}_{55}\right)$, or the higher-ranked SONHIER constraint *s $\left(\mathrm{O}_{11}\right)$. Consequently, GMCOR will have to be violated, and the decision is handed over to the SONHIER constraints, which select /e/, as in $\mathrm{O}_{15} \cdot{ }^{34}$

To sum up so far, agreement marking (weak inflection) is triggered on adjectives by a Case-marked determiner. However, AGR does not specifically mention Case-marked determiners. It is more general since it requires an agreement marker on an adjective whenever there is a non-adjectival head in the same minimal residue that bears a Case marker. This makes interesting predictions for syntactic environments where there is no determiner present, but a Case-marked noun. This leads to the issue of strong adjective inflection.

\footnotetext{
${ }^{33}$ Recall from $\mathrm{T}_{4}$ that $/ \mathrm{m} /$ violates $*$ SONCM as a Case marker in this context, but that all competitors violate higher-ranked constraints in $* \mathrm{XCM}$.

${ }^{34}$ The question arises of whether a more general formulation of GMCOR is feasible that dispenses with a restriction to [+masc, +gov] contexts. This would raise certain problems. To name just one, the Case marker/R/ in NOM.MASC contexts should also be imposed on the agreement marker, as in *dieser guter (Tee) ('this good tea ${ }_{n o m}$ ') instead of dieser gute (Tee): a NOM.MASC agreement marker does not have to obey *DAM.
} 
$T_{13}$ : dieses gute (Bier)

\begin{tabular}{|l||c|c|c|c|c|c|c|c|c|c|}
\hline $\begin{array}{l}\text { I: /dies, gut/: } \\
\text { ACC.N }\end{array}$ & AGR & CASE & $\begin{array}{c}* \mathrm{D} \\
\text { AM }\end{array}$ & $\begin{array}{c}* \mathrm{X} \\
\mathrm{CM}\end{array}$ & $* \mathrm{~s}$ & $* \mathrm{~m}$ & $\begin{array}{c}\text { GM } \\
\text { COR }\end{array}$ & $* \mathrm{n}$ & $* \mathrm{R}$ & $* \mathrm{e}$ \\
\hline \hline $\mathrm{O}_{11}:$ dieses gutes & & & & & $* * !$ & & & $*$ & & \\
\hline $\mathrm{O}_{12}:$ dieses gutem & & & & & $*$ & $* !$ & $*$ & & & \\
\hline $\mathrm{O}_{13}:$ dieses guten & & & & & $*$ & & $*$ & $* !$ & & \\
\hline $\mathrm{O}_{14}:$ dieses guter & & & & & $*$ & & $*$ & & $* !$ & \\
\hline $\mathrm{O}_{15}:$ dieses gute & & & & & $*$ & & $*$ & & & $*$ \\
\hline $\mathrm{O}_{16}:$ dieses gut & $* !$ & & & & $*$ & & $*$ & & & \\
\hline $\mathrm{O}_{22}:$ diesem gutem & & & & $* !$ & & $* *$ & & & & \\
\hline $\mathrm{O}_{33}:$ diesen guten & & & & $* !$ & & & & $* *$ & & \\
\hline $\mathrm{O}_{44}:$ dieser guter & & & & $* !$ & & & & & $* *$ & \\
\hline $\mathrm{O}_{55}:$ diese gute & & & & $* !$ & & & & & & $* *$ \\
\hline
\end{tabular}

\subsection{Strong inflection}

The paradigm $\mathrm{P}_{8}$ for strong adjective inflection is almost identical to the determiner inflection paradigm $\mathrm{P}_{1}$. The only difference is that GEN.MASC and GEN.NEUT specifications employ $/ \mathrm{n} /$ rather than $/ \mathrm{s} /$.

$P_{8}:$ Strong adjective inflection

\begin{tabular}{|l|c|c|c|c|}
\hline gut & M.SG & N.SG & F.SG & PL \\
\hline \hline NOM & er & es & e & e \\
\hline ACC & en & es & e & e \\
\hline DAT & em & em & er & en \\
\hline GEN & en & en & er & er \\
\hline
\end{tabular}

Strong adjective inflection is used in an NP whenever there is no preceding determiner; compare (11) with (8).

(11) NOM guter Tee, gutes Bier, gute Milch, gute Gläser ACC guten Tee, gutes Bier, gute Milch, gute Gläser DAT gutem Tee, gutem Bier, guter Milch, guten Gläsern GEN guten Tees, guten Bieres, guter Milch, guter Gläser 'good tea (MASC), good beer (NEUT), good milk (FEM), good glasses (PL)'

This basic distributional pattern follows directly from the approach developed so far: CASE requires a Case marker on the left edge of the minimal residue of an NP, and if there is no determiner that can provide a Case marker, the leftmost item that can in principle bear a Case marker must do so. Hence, an adjective in this syntactic environment requires a Case marker, with AGR being vacuously satisfied if there is no other Case marker present. ${ }^{35}$

The problem that remains to be solved, then, is the fact that a [+masc,+obl,-gov] specification requires $/ \mathrm{n} /$, not $/ \mathrm{s} /$ as a Case marker; recall from tableau $\mathrm{T}_{5}$ that $/ \mathrm{n} /$ should be blocked

\footnotetext{
${ }^{35}$ Strong adjective inflection is also chosen in contexts where the adjective is preceded only by an NP, as in Karls guter Tee ('Karl's good tea'). Given that the prenominal NP bears a possessive(-like) marker here and cannot participate in NP-internal Case inflection for principled reasons, the present analysis implies that CASE must be violated by a well-formed output in this context (since the leftmost item in SR cannot receive a Case marker), but that this violation must be kept minimal (so that the leftmost item in SR that can receive a Case marker - viz., the adjective - is indeed Case marked).
} 
in this context as a Case marker because of a fatal $*$ SONCM violation that (of all the potential Case markers) only /s/ manages to avoid. Closer inspection reveals that this dilemma persists only as long as we take paradigms to be independently existing objects that are formed extrasyntactically. If we abandon this hypothesis, as I do here, there is nothing that would demand a homogeneous status of the markers in $\mathrm{P}_{8}$. Thus, I would like to suggest that whereas most of the markers in $\mathrm{P}_{8}$ are indeed Case markers, some are agreement markers whose presence is required by a Case marker - not a Case marker on the determiner (as in all the cases considered so far), but a Case marker on the noun. ${ }^{36}$ If this view is essentially correct, we are dealing with a clear case of contextually determined inflection, which supports the general perspective adopted here.

To execute the idea, it turns out that one additional assumption has to be made: The partitioning of CASE into two subconstraints (1-a) and (1-b) has not played a role so far, but it does now: CASERight (CR, (1-b)) must be ranked higher than CASELEFT (CL, (1-a)). With this in mind, consider first an example where strong adjective inflection and determiner inflection converge. Given, e.g., a NOM.MASC ([+masc,-fem,-obl,-gov]) specification on an adjective and a noun in a determinerless NP input, the optimal output has a Case marker $/ \mathrm{R} /$ on the adjective (compare $\mathrm{T}_{2}$ ), and no Case marker on the noun (compare $\mathrm{T}_{6}$, which has another input specification but illustrates the relevance of $* \mathrm{NCM}$ ). This is shown in tableau $\mathrm{T}_{14}$ (which does not consider outputs that fatally violate * $\mathrm{NCM}$ by having a Case marker on $\mathrm{N}$ ). Note that higher-ranked AGR is vacuously fulfilled because there is no adjective that shares a minimal residue with a Case marker on a non-adjectival head.

$T_{14}:$ guter Tee

\begin{tabular}{|l||c|c|c|c|c|c|c|c|c|c|c|}
\hline $\begin{array}{l}\text { I: /gut, Tee/: } \\
\text { NOM.M }\end{array}$ & AGR & $\mathrm{C}$ & $\mathrm{C}$ & $* \mathrm{D}$ & $* \mathrm{X}$ & $* \mathrm{~s}$ & $* \mathrm{~m}$ & $\mathrm{GM}$ & $* \mathrm{n}$ & $* \mathrm{R}$ & $* \mathrm{e}$ \\
\hline \hline $\mathrm{O}_{16}:$ gutes Tee & & $*$ & & & & $* !$ & & & & & \\
\hline $\mathrm{O}_{26}:$ gutem Tee & & $*$ & & & & & $* !$ & & & & \\
\hline $\mathrm{O}_{36}:$ guten Tee & & $*$ & & & & & & & $* !$ & & \\
\hline $\mathrm{O}_{46}:$ guter Tee & & $*$ & & & & & & & & $*$ & \\
\hline $\mathrm{O}_{56}:$ gute Tee & & $*$ & & & $* !$ & & & & & & $*$ \\
\hline $\mathrm{O}_{66}:$ gut Tee & & $*$ & $* !$ & & & & & & & & \\
\hline
\end{tabular}

Consider next a [+masc,+obl,-gov] specification. What is interesting about this context is that optimization leads to a Case marker/s/ on a noun with this specification because *NCM is not violated (see $\mathrm{T}_{7}$ above). Now, a conflict may arise between AGR and CASELEFT: By virtue of being the leftmost head that can receive a Case marker, the adjective should bear a Case marker to satisfy CASELEFT; and by virtue of being an adjective that co-occurs with a non-adjective (i.e., a noun) with a Case marker in the same minimal residue, the adjective should bear an agreement marker. Given that a marker cannot serve both Case and agreement, the conflict must be resolved by ranking, and given the ranking AGR $\gg$ CASELEFT, agreement prevails. Therefore, the optimal marker in this context is $/ \mathrm{n} /$, and not $/ \mathrm{s} /$. This reasoning is illustrated in tableau $\mathrm{T}_{15}$ on the basis of the specification [+masc,-

\footnotetext{
${ }^{36}$ This approach builds on an insight in Eisenberg $(2000,173)$, who concludes that the "fixed grammaticalization" of $e n$ in GEN.MASC and GEN.NEUT contexts of strong adjective inflection can be traced back to strong inflection on the noun itself.
} 
fem,+obl,-gov].

$T_{15}:$ guten Tees

\begin{tabular}{|c|c|c|c|c|c|c|c|c|c|c|c|}
\hline $\begin{array}{l}\text { I: /gut, Tee/: } \\
\text { GEN.M }\end{array}$ & AGR & $\begin{array}{l}\mathrm{C} \\
\mathrm{R}\end{array}$ & $\begin{array}{l}\mathrm{C} \\
\mathrm{L}\end{array}$ & $\begin{array}{l}* \mathrm{D} \\
\mathrm{AM}\end{array}$ & $\begin{array}{l}* X \\
\text { CM }\end{array}$ & $*_{\mathrm{s}}$ & $*_{\mathrm{m}}$ & $\begin{array}{l}\text { GM } \\
\text { COR }\end{array}$ & $* n$ & ${ }^{*} \mathrm{R}$ & $* \mathrm{e}$ \\
\hline$\overline{\mathrm{O}_{11}}$ : gutes Tees & $(* ! C)$ & & $\overline{(* \mathrm{~A})}$ & & & *(*!A) & & & & & \\
\hline $\mathrm{O}_{16}:$ gutes Tee & & $* !$ & $(* \mathrm{~A})$ & & & * & & & & & \\
\hline $\mathrm{O}_{31}$ : guten Tees & $(* ! C)$ & & $(* \mathrm{~A})$ & & $\left({ }^{*} \mathrm{C}\right)$ & * & & & $*$ & & \\
\hline $\mathrm{O}_{36}:$ guten Tee & & $* !$ & $(* \mathrm{~A})$ & & $(* \mathrm{C})$ & & & & $*$ & & \\
\hline $\mathrm{O}_{66}:$ gut Tee & & $* !$ & * & & & & & & & & \\
\hline
\end{tabular}

For each marker on the adjective, a decision must be made as to whether it acts as a Case marker or as an agreement marker; this is expressed in the tableau by attributing each violation where the decision matters to the interpretation as a Case marker $\left({ }^{*} \mathrm{C}\right)$ or as an agreement marker $(* \mathrm{~A}) . \mathrm{O}_{31}$ is the optimal output: If the marker $/ \mathrm{n} /$ on the adjective is interpreted as an agreement marker, CASELEFT is violated, but the higher-ranked constraints AgR and CASERIGHT are respected. All other choices of agreement marker form (e.g., /s/ in $\mathrm{O}_{11}$ ) incur fatal violations of the constraints that regulate agreement markers $\left({ }^{*} \mathrm{~s}\right.$, in the case at hand); see $\mathrm{T}_{10}$. In all outputs in which the marker on the adjective is interpreted as a Case marker, we end up with a fatal violation of either AGR (if there is a Case marker on the noun; in particular, this holds for $\mathrm{O}_{11}$ if /s/ is interpreted as a Case marker) or CASERIGHT (if there is no Case marker on the noun, and an agreement marker is not required).

This approach has a further consequence that is theoretically interesting, but empirically vacuous. Recall from $\mathrm{T}_{8}$ that there is a second context in which a noun is Case marked in German, viz., DAT.PL. Hence, the analysis given for GEN.MASC, GEN.NEUT /n/ vs. /s/ in the case of strong adjective inflection automatically predicts that in DAT.PL forms like guten Büchern ('good books') (though not in DAT.PL forms like guten Opas 'good grandfathers'), $\mathrm{ln} /$ on the adjective is not a Case marker, but an agreement marker (or, using the standard terminology, the adjective in guten Büchern shows weak inflection even though a determiner is absent). ${ }^{37}$

I would like to contend that the system developed so far captures the gist of the weak/strong distinction with adjective inflection. Of course, in a comprehensive account, more will ultimately have to be said about certain exceptions, idiosyncracies, and, perhaps most importantly, cases of optionality. However, it seems to me that it will not be difficult to integrate most of these complications (e.g., by invoking faithfulness constraints that refer to lexically marked properties, by resorting to variable ranking or constraint ties, by motivating recategorization procedures, etc.), and leave the core of the present proposal unaffected. ${ }^{38}$

\footnotetext{
${ }^{37}$ Note in passing that this argument reinforces the decision to exclude archaic DAT.MASC, DAT.NEUT /e/ on nouns from the productive system of nominal inflection in the present analysis. If /e/ on a noun were to act as a Case marker triggered by CASERIGHT, we should wrongly expect agreement marking to prevail on the adjective, yielding ill-formed *aus harten Holze ('of solid wood') instead of aus hartem Holze.

${ }^{38} \mathrm{~A}$ particularly well-known case of optionality concerns the tendency of certain determiners to take on markers of the strong adjective inflection paradigm, as in (Januar) diesen Jahres ('January this year ${ }_{\text {gen }}$ ') alongside the expected (Januar) dieses Jahres. This effect might be captured by optional recategorization procedures $(\mathrm{D} \rightarrow \mathrm{A})$, by genuine output/output constraints, or some related means; but I will leave this question open here. See Zifonun et al. (1997, 1928-1950) for further remarks, and for an overview of the variation encountered in
} 
Still, there is one kind of systematic exception that has received a lot of attention in the literature, viz., the phenomenon of "mixed inflection".

\subsection{Mixed inflection}

$\mathrm{P}_{9}$ gives the mixed adjective inflection paradigm as it can be found in, e.g., Eisenberg (2000, 172). The standard generalization is that an adjective inflects according to this pattern if it follows a determiner belonging to a certain class that includes ein ('a'), kein ('no'), and mein ('my'), among others.

\section{$P_{9}$ : Mixed adjective inflection}

\begin{tabular}{|l|c|c|c|c|}
\hline gut & M.SG & N.SG & F.SG & PL \\
\hline \hline NOM & er & es & e & en \\
\hline ACC & en & es & e & en \\
\hline DAT & en & en & en & en \\
\hline GEN & en & en & en & en \\
\hline
\end{tabular}

$\mathrm{P}_{9}$ is identical to the weak inflection paradigm, except for the "strong" forms in NOM.MASC, NOM.NEUT, and ACC.NEUT contexts. Accordingly, this paradigm is often not accorded a status of its own, but is argued to arise on the basis of the other two inflection paradigms (see, e.g., Zwicky 1986). The mixed paradigm provides yet another clear case of contextually determined inflection: The syntactic environment that triggers the choice of a strong form in a post-determiner position has another property that evidently acts as the trigger: In NOM.MASC, NOM.NEUT, and ACC.NEUT contexts, determiners like kein are incompatible with the expected strong inflection themselves; hence, the adjective takes over the task of expressing strong inflection in these contexts (and only in these); see (12).

(12) NOM kein guter Tee, kein gutes Bier, keine gute Milch, keine guten Gläser ACC keinen guten Tee, kein gutes Bier, keine gute Milch, keine guten Gläser DAT keinem guten Tee, keinem guten Bier, keiner guten Milch, keinen guten Gläsern GEN keines guten Tees, keines guten Bieres, keiner guten Milch, keiner guten Gläser 'no good tea (MASC), no good beer (NEUT), no good milk (FEM), no good glasses (PL)'

This explanation can be integrated into the present analysis as follows. Suppose that there is a constraint * DECM outranking CASELEFT which yields the effect that determiners with certain features (morpho-phonological features, semantic features, or a combination thereof) are incompatible with a Case marker in NOM.MASC, NOM.NEUT, and ACC.NEUT contexts. Then, CASELEFT will have to be violated in these contexts, but given that this constraint is gradient, its violation can and, therefore, must be kept minimal by placing a Case marker on an adjective that follows the Case marker-less determiner. ${ }^{39}$ This is shown for an ACC.NEUT specification in the input in tableau $\mathrm{T}_{16}$, which lists only three relevant candidates $-\mathrm{O}_{15}$, which we would expect to be optimal without the overriding effect of $* \mathrm{DECM}$ (compare

\footnotetext{
this domain with different types of determiners.

${ }^{39}$ If there is no adjective in the input, a violation of CASELEFT cannot be minimized - kein Tee ('no tea ${ }_{\text {nom }}$ ') and Karls Tee ('Karl's tea') violate CASELEFT and CASERIGHT in exactly the same way.
} 
$\mathrm{T}_{13}$ ), $\mathrm{O}_{61}$, which is optimal, and $\mathrm{O}_{65}$, which fatally violates either CASELEFT (by having an uncalled-for agreement marker) or $* \mathrm{VCM}$ (by choosing a suboptimal Case marker form). (Irrelevant constraints like $\mathrm{CR}$ and $* \mathrm{DAM}$ are left out in $\mathrm{T}_{16}$.)

$T_{16}$ : kein gutes (Bier)

\begin{tabular}{|c||c|c|c|c|c|c|c|c|c|c|}
\hline $\begin{array}{l}\mathrm{I}: / \text { kein, gut/: } \\
\text { ACC. } \mathrm{N}\end{array}$ & $\begin{array}{c}* \mathrm{DE} \\
\mathrm{CM}\end{array}$ & AGR & $\begin{array}{c}\mathrm{C} \\
\mathrm{L}\end{array}$ & $\begin{array}{c}* \mathrm{X} \\
\mathrm{CM}\end{array}$ & $* \mathrm{~s}$ & $* \mathrm{~m}$ & $\begin{array}{c}\mathrm{GM} \\
\mathrm{COR}\end{array}$ & $* \mathrm{n}$ & $* \mathrm{R}$ & $* \mathrm{e}$ \\
\hline \hline $\mathrm{O}_{15}:$ keines gute & $* !$ & & & & $*$ & & $*$ & & & $*$ \\
\hline $\mathrm{O}_{61}:$ kein gutes & & & $*$ & & $*$ & & $*$ & & & \\
\hline $\mathrm{O}_{65}:$ kein gute & & & $*(* ! \mathrm{A})$ & $(* ! \mathrm{C})$ & & & $*$ & & & $*$ \\
\hline
\end{tabular}

In contrast, in all those environments where ${ }^{*} \mathrm{DECM}$ permits a Case marker on a determiner like kein, the CASELEFT violation incurred by candidates of the $\mathrm{O}_{61}$ type will be fatal, and inflection proceeds exactly as shown in subsection 4.1.

\subsection{Adjective sequences}

I have not yet addressed NPs with more than one adjective, i.e., more than one AP specifier. Given AGR, all adjectives in SpecN positions require an agreement marker if there is a Case marker on either a determiner or a noun in the same minimal residue, and this prediction is correct. The more interesting case is provided by multiple adjective enviroments without a Case marker on a non-adjective nearby. As we have seen, the first adjective must then have a Case marker, because of CASELEFT. But what about adjectives that follow the first one? CASELEFT does not require a Case marker here, and AGR does not require an agreement marker (because the Case marker is on an adjective, i.e., the same type of head). Thus, if nothing else is said, the prediction is that non-first adjectives in these environments have no marker at all. This prediction is not borne out, though. With one exception (DAT.MASC, DAT.NEUT), these adjectives must have the same marker that the first adjective has; see (13).

(13) NOM guter alter/*e Tee, gutes altes/*e Bier, gute alte Milch, gute alte/*n Gläser ACC guten alten Tee, gutes altes/*e Bier, gute alte Milch, gute alte/*n Gläser

DAT gutem altem/?n Tee, gutem altem/?n Bier, guter alter/*n Milch, guten alten Gläsern

GEN guten alten Tees, guten alten Bieres, guter alter/*n Milch, guter alter/*n Gläser 'good old tea (MASC), good old beer (NEUT), good old milk (FEM), good old glasses (PL)'

Thus, the following constraint suggests itself.

(14) ADJCOR (Adjective Correspondence):

Adjectives in the same minimal residue have identical markers.

Assuming that ADJCOR dominates the SONHIER constraints, the uniformity effect visible in German adjective sequences follows. This is shown for a NOM.MASC input specification in tableau $\mathrm{T}_{17}$. Note in particular that ADJCOR successfully blocks a (superfluous) agreement marker and non-marking on the non-first adjective $\left(\right.$ see $\mathrm{O}_{456}, \mathrm{O}_{466}$ ), by forcing marker identity. $\mathrm{O}_{446}$ then has a better constraint profile than, e.g., $\mathrm{O}_{556}$ for the same reason that $\mathrm{O}_{46}$ has a better constraint profile than $\mathrm{O}_{56}$ in $\mathrm{T}_{14}$. 
$T_{17}:$ guter alter Tee

\begin{tabular}{|l||c|c|c|c|c|c|c|c|c|c|c|}
\hline $\begin{array}{l}\text { I: /gut, alt, Tee/: } \\
\text { NOM.M }\end{array}$ & ADJ & AGR & C & C & $*$ X & $* \mathrm{~s}$ & $* \mathrm{~m}$ & GM & $* \mathrm{n}$ & $* \mathrm{R}$ & $* \mathrm{e}$ \\
\hline \hline $\mathrm{O}_{446}:$ guter alter Tee & & & $*$ & & & & & & & $* *$ & \\
\hline $\mathrm{O}_{456}:$ guter alte Tee & $* !$ & & $*$ & & & & & & & $*$ & $*$ \\
\hline $\mathrm{O}_{466}:$ guter alt Tee & $* !$ & & $*$ & & & & & & & $*$ & \\
\hline $\mathrm{O}_{556}:$ gute alte Tee & & & $*$ & & $* !$ & & & & & & $* *$ \\
\hline
\end{tabular}

Consider now the DAT.MASC, DAT.NEUT context in 2. As shown in tableau $\mathrm{T}_{18}$, the present analysis predicts $\mathrm{O}_{226}$, with identical Case markers, to be the sole optimal output. However, whereas $\mathrm{O}_{226}$ is indeed well formed for all speakers, many speakers also accept $\mathrm{O}_{236}$, without matching markers. Thus, for a [+masc,+obl,+gov] specification, and for this specifcation only, marker identity is not necessarily imposed on adjective sequences, and optionality may arise. (As with most instances of optionality, speakers that permit both options may then associate functional or minor semantic differences with the two options.)

$T_{18}$ : gutem altem Tee

\begin{tabular}{|l||c|c|c|c|c|c|c|c|c|c|c|}
\hline I: /gut, alt, Tee/: & ADJ & AGR & C & C & $* \mathrm{X}$ & $* \mathrm{~s}$ & $* \mathrm{~m}$ & $\mathrm{GM}$ & $* \mathrm{n}$ & ${ }^{*} \mathrm{R}$ & ${ }^{*} \mathrm{e}$ \\
DAT.M & $\mathrm{COR}$ & & $\mathrm{R}$ & $\mathrm{L}$ & $\mathrm{CM}$ & & & $\mathrm{COR}$ & & & \\
\hline \hline $\mathrm{O}_{226}:$ gutem altem Tee & & & $*$ & & $*$ & & $* *$ & & & & \\
\hline $\mathrm{O}_{236}:$ gutem alten Tee & $* !$ & & $*$ & & $*$ & & $*$ & $*$ & $*$ & & \\
\hline
\end{tabular}

It is unclear to me whether one should account for the optional availability of $\mathrm{O}_{236}$ in the same way in which the optimality of $\mathrm{O}_{226}$ is derived. At least for present purposes, it seems preferable to classify $\mathrm{O}_{236}$ as not resulting from the core system of nominal inflection in present-day German. Arguably, its existence can successfully be traced back to the influence of analogy (the $/ \mathrm{m} /-\mathrm{n} / \mathrm{s}$ sequence of Case and agreement markers is both formally conspicuous and frequent); like other instances of analogy, this could be formulated in terms of output/output constraints. ${ }^{40}$

\subsection{Weak noun inflection}

Let me finally turn to the inflection of weak masculine nouns, which was alluded to, but not addressed, in section 3. What follows is a brief sketch of how weak masculine nouns might fit into the overall approach pursued here. Paradigm $\mathrm{P}_{10}$ lists the markers for weak masculine nouns like Dirigent ('conductor') and Bote ('messenger'). Presence or absence of $e$ depends on the nature of the coda of the stem (consonantal or vocalic); we can thus assume $/ \mathrm{n} /$ as the sole marker. ${ }^{41}$

Clearly, the present analysis does not support the idea that we are dealing with a second

\footnotetext{
${ }^{40}$ Note in passing that it would not be possible to simply assume that ADJCOR can be tied with *m. Under this assumption, *gutem alt Tee ('good old tea') would optionally become optimal, rather than the intended gutem alten Tee (recall that there is no trigger for an agreement marker here). Moreover, *s would now invariably outrank ADJCOR, and a well-formed NP like gutes altes Bier ('good old beer') should not be possible anymore.

${ }^{41}$ The plural marker for weak masculine nouns is uniformly /n/; hence, Case marking in the plural can be ignored.
} 
$P_{10}:$ Weak masculine noun inflection

\begin{tabular}{|l|c||l|c|}
\hline Dirigent & M.SG & Bote & M.SG \\
\hline \hline NOM & & NOM & \\
\hline ACC & en & ACC & $\mathrm{n}$ \\
\hline DAT & en & DAT & $\mathrm{n}$ \\
\hline GEN & en & GEN & $\mathrm{n}$ \\
\hline
\end{tabular}

type of Case marking on masculine nouns here; this would lead directly to the postulation of declension class features, an assumption that is otherwise not necessary in German, and perhaps dispensable even for other languages (see Wunderlich (1996) and Fraser \& Corbett (1995) for opposing views). In fact, we have theory-internal evidence that the markers in $\mathrm{P}_{10}$ are not Case markers at all. First, the interaction of FCRs for Case markers and the SoNHIER constraint preclude $/ \mathrm{n} /$ as a marker in DAT.MASC and GEN.MASC contexts. Second, in contrast to what we have seen with true Case markers in subsection 4.2, the GEN marker $/ \mathrm{n} /$ of a weak masculine noun fails to trigger the (AGR-induced) change from $/ \mathrm{s} /$ to $/ \mathrm{n} /$ : In the marginal cases in which a masculine noun that is [+animate] (which is the prototypical feature of weak masculine nouns) can occur without a determiner in GEN contexts at all, a regular masculine noun induces agreement marking on a preceding adjective; see (15-a) vs. (15-b). However, a weak masculine noun fails to induce $/ \mathrm{n} /$ on the preceding adjective; in addition, in this environment, presence of /s/ is actually somewhat more acceptable than with regular masculine nouns; see (15-c) vs. (15-d).

(15) (Aber das muss er doch tun! Das ist doch ...)

('But he has to do that! This is ...')

a. ?guten Mannes Pflicht

b. *gutes Mannes Pflicht

'good man ${ }_{g e n}$ duty'

c. *guten Jungen Pflicht

d.??gutes Jungen Pflicht

'good boy ${ }_{g e n}$ duty'

If the $/ \mathrm{n} /$ markers on weak masculine nouns are not Case markers, the question arises of what else they might be. Here I would like to suggest that they are agreement markers. Thus, suppose that weak masculine nouns, as a lexical property, underlie AGR, and that there is a higher-ranked constraint which precludes their bearing a NOM marker. We have seen that agreement markers can only arise in the presence of Case markers. Hence, if a Case marker is present in the SR, a weak masculine noun in the HR of the same minimal residue will receive an agreement marker $/ \mathrm{n} /$ in ACC, DAT, and GEN contexts, as shown in subsection 4.1 (and no marker at all in NOM contexts). If, on the other hand, there is no Case marker present in the same NP (because there is no determiner or adjective available in the input), the weak masculine noun will not receive a marker. This way, Gallmann's $(1996 ; 1998)$ observation is derived that (ACC or DAT) $/ \mathrm{n} /$ markers on weak masculine nouns require an inflecting adjective or determiner in the same domain: (16-a) blocks (16-b) as suboptimal because the latter fatally violates AGR, whereas (16-c) is blocked by (16-d) because the former fatally violates $* \mathrm{n}$ (in the absence of a trigger for an agreement marker).

(16) a. (ein Orchester mit) [NP eigenem Dirigenten ] 
b. *(ein Orchester mit) [NP eigenem Dirigent ]

c. *(ein Orchester mit) [NP Dirigenten ]

d. (ein Orchester mit) [NP Dirigent ]

'an orchestra with (own) conductor'

The ranking AGR $\gg$ CASERIGHT ensures that in the case of conflict, a weak masculine noun will choose agreement marking over Case marking. However, given the high-ranked constraint $* \mathrm{NCM}$, there is no potential conflict, except for GEN environments. Here, agreement marking prevails if a pre-nominal determiner (or, marginally, adjective - see above) is present; compare des Dirigenten ('the conductor ${ }_{\text {gen }}$ ') with *des Dirigents. Still, there is a single context in which the present approach could wrongly predict a Case marker to occur on a weak masculine noun, viz., GEN environments without a preceding determiner. Thus, it seems that the optimal form should now be *Dirigents instead of Dirigent. However, as noted by Gallmann $(1996 ; 1998)$ something needs to be said for these cases anyway: Irrespective of the question of whether a suitable sentence could be construed into which an NP with a bare weak masculine noun could fit, other masculine or neuter nouns turn out to be impossible as bare GEN NPs as well; see, e.g., Gallmann's examples (die Verarbeitung) *Holzes ('the manufacturing wood $_{\text {gen }}$ ') and (die Herstellung) *Betons ('the production concrete ${ }_{g e n}$ '). Thus, whatever is responsible for this ban on GEN NPs headed by bare nouns in general is likely to also cover the subcase of bare masculine nouns.

\section{Conclusion}

To conclude, I have developed an optimality-theoretic approach to nominal inflection in German that determines the form and the distribution of inflection markers in one and the same syntactic component (and, in doing so, dispenses with the hypothesis that nominal inflection paradigms are linguistic objects in their own right, as well as with the standard assumption that German nominal inflection markers are morphemes); and I have tried to argue that such an approach is both viable and independently supported (given the importance of the syntactic environment for the choice of inflection marker, and the partial, sonority-based motivation for the shape of nominal inflection markers). I have argued that there are two kinds of inflection markers in the NP domain: Case markers and agreement markers, the latter dependent on the presence of the former. The analysis relies on four types of constraints. CASE (decomposable into CASELEFT and CASERIGHT) and AGR are the main triggers for Case and agreement markers, respectively. The form of inflection markers is determined by the interaction of low-ranked SONHIER constraints (i.e., the sonority hierarchy: ${ }^{*} \mathrm{~s} \gg *_{\mathrm{m}}$ $\gg * n \gg * \mathrm{R} \gg *^{*} \mathrm{e}$ ) and higher-ranked feature co-occurrence restrictions (FCRs) which correlate morpho-syntactic features and phonological features, relativized with respect to Case and agreement markers $(* \mathrm{X} / \mathrm{CM}, * \mathrm{X} / \mathrm{AM})$. Finally, in addition to inflection triggers, the sonority hierarchy, and FCRs, the approach employs a fourth type of constraint, viz., correspondence constraints on markers (GMCOR, ADJCOR); these constraints require marker identity in certain domains and can thereby also act as triggers for inflection marking.

Needless to say, the analysis given here has left open many questions, both empirically and theoretically. On the empirical side, it is clear that a fully comprehensive account would have to say more in various domains: e.g., in the case of lexically determined variation and 
partial optionality with some lexical items, particularly determiners, or in the case of certain additional restrictions on inflection marking in GEN NPs. On the theoretical side, an obvious question concerns the status of the constraints invoked here. A standard assumption in optimality theory is that the ranked constraints used for harmony evaluation are universal. Viewed from this perspective, CASE and AGR, the SONHIER subhierarchy, and the marker identity constraints are arguably acceptable. The relativized FCRs certainly have a highly specific shape; still, they exhibit similar patterns. One might speculate that these constraints are not universal as such, but can be generated in a language by (i) taking universal morphosyntactic and phonological features as basic, (ii) combining the features by Boolean operations, and (iii) correlating the specifications of morpho-syntactic features and phonological features achieved this way by logical implication. On this view, what would be universal is not a FCR per se, but the vocabulary that it uses, and the scheme that it employs. ${ }^{42}$ For the moment, I have to leave these and other questions open.

\section{References}

Aissen, Judith (2000). Differential object marking: Iconicity vs. economy. Unpublished manuscript, University of California, Santa Cruz.

Anderson, Stephen (1992). A-Morphous Morphology. Cambridge: Cambridge University Press.

Bierwisch, Manfred (1967). Syntactic features in morphology: general problems of so-called pronominal inflection in German. In To Honour Roman Jakobson, 239-270. Mouton: The Hague/Paris.

Blevins, James (1995). Syncretism and paradigmatic opposition. Linguistics and Philosophy $18,113-152$.

Chomsky, Noam (1995). The Minimalist Program. Cambridge, Mass.: MIT Press.

Chomsky, Noam (2001). Derivation by phase. In Ken Hale. A Life in Language, Michael Kenstowicz (ed.), 1-52. Cambridge, Mass.: MIT Press.

Eisenberg, Peter (2000). Grundriß der deutschen Grammatik. Band 1: Das Wort. Stuttgart: Metzler.

Elgersma, Diana \& Paul Houseman (1999). Optimality theory and natural morphology: An analysis of German plural formation. Folia Linguistica 33, 334-353.

Fraser, Norman \& Greville Corbett (1995). Gender, animacy, and declension class assignment: A unified account for Russian. In Yearbook of Morphology 1994, Geert Booij \& Jaap van Marle (eds.), 123-150. Dordrecht: Kluwer.

Gallmann, Peter (1996). Die Steuerung der Flexion in der DP. Linguistische Berichte 164, 283-314.

Gallmann, Peter (1998). Case underspecification in morphology, syntax and the lexicon. In Possessors, Predicates and Movement in the Determiner Phrase, Artemis Alexiadou \& Chris Wilder (eds.), 141-175. Amsterdam: Benjamnis.

Gazdar, Gerald, Ewan Klein, Geoffrey Pullum \& Ivan Sag (1985). Generalized Phrase Structure Grammar. Oxford: Blackwell.

\footnotetext{
${ }^{42}$ Similar considerations apply in the case of the two constraint generation mechanisms harmonic alignment and constraint conjunction that have been suggested in Prince \& Smolensky (1993) and Smolensky (1995), respectively.
} 
Gelhaus, Hermann (1998). Die Wortarten. In Duden: Die Grammatik. Mannheim: Dudenverlag.

Golston, Chris \& Richard Wiese (1996). Zero morphology and constraint interaction: subtraction and epenthesis in German dialects. In Yearbook of Morphology 1995, Geert Booij \& Jaap van Marle (eds.), 143-159. Dordrecht: Kluwer.

Grimshaw, Jane (1997). Projection, heads, and optimality. Linguistic Inquiry 28, 373-422.

Grimshaw, Jane (2001). Optimal clitic positions and the lexicon in Romance clitic systems. In Optimality-Theoretic Syntax, Géraldine Legendre, Jane Grimshaw \& Sten Vikner (eds.), 205-240. Cambridge, Mass.: MIT Press.

Halle, Morris (1994). The Russian declension: An illustration of the theory of distributed morphology. In Perspectives in Phonology, Jennifer Cole and Charles Kisseberth (eds.), 29-60. Stanford: CSLI Publications.

Heck, Fabian \& Gereon Müller (2000). Repair-driven movement and the local optimization of derivations. Unpublished manuscript, Universität Stuttgart \& IDS Mannheim.

Hoberg, Ursula (2001). Das Genus des Nomens. Unpublished manuscript, IDS Mannheim.

Ito, Junko, \& Armin Mester (2001). Structure Preservation and Stratal Opacity in German. In Segmental Phonology in Optimality Theory, Linda Lombardi (ed.), 261-295. Cambridge: Cambridge University Press.

Kiparsky, Paul (1982). From cyclic phonology to lexical phonology. In The Structure of Phonological Representations, vol. 1, Harry van der Hulst \& Neil Smith (eds.), 131175. Dordrecht: Foris.

Legendre, Géraldine, Paul Smolensky \& Colin Wilson (1998). When is less more? Faithfulness and minimal links in wh-chains. In Is the Best Good Enough?, Pilar Barbosa et al. (eds.), 249-289. Cambridge, Mass.: MIT Press \& MITWPL.

McCarthy, John, \& Alan Prince (1995). Faithfulness and reduplicative identity. In Papers in Optimality Theory, Jill Beckman, Laura Walsh-Dickie \& Suzanne Urbanczyk (eds.), 249-384. Amherst, Massachussetts: UMass Occasional Papers in Linguistics 18.

Müller, Gereon (2001). Free word order, morphological case, and sympathy theory. Unpublished manuscript, IDS Mannheim. To appear in Resolving Conflicts in Grammar: More Papers on OT, Gisbert Fanselow \& Caroline Féry (eds.). (Special Issue of Linguistischen Berichte).

Neef, Martin. 1998. A Case Study in Declarative Morphology: German Case Inflection. In Phonology and Morphology of the Germanic Languages, eds. Wolfgang Kehrein \& Richard Wiese, 219-240. Tübingen: Niemeyer.

Prince, Alan \& Paul Smolensky (1993). Optimality Theory. Constraint Interaction in Generative Grammar. Unpublished manuscript, Rutgers University. To appear: Cambridge, Mass.: MIT Press.

Ross, John (1980). Ikonismus in der Phraseologie. Zeitschrift für Semiotik 2, 39-56.

Samek-Lodovici, Vieri (2001). Agreement impoverishment under subject inversion. A crosslinguistic analysis. Unpublished manuscript, UC London. To appear in Resolving Conflicts in Grammar: More Papers on OT, Gisbert Fanselow \& Caroline Féry (eds.). (Special Issue of Linguistischen Berichte).

Smolensky, Paul (1995). On the internal structure of Con, the constraint component of UG. Unpublished manuscript, Johns Hopkins University.

Stump, Gregory (2001). Inflectional Morphology. Cambridge: Cambridge University Press. Tesar, Bruce \& Paul Smolensky (2000). Learnability in Optimality Theory. Cambridge, 
Mass.: MIT Press.

Wegener, Heide (1999). Die Pluralbildung im Deutschen - ein Versuch im Rahmen der Optimalitätstheorie. Linguistik Online 4, 3/99.

Wiese, Bernd (1996). Iconicity and syncretism. On pronominal inflection in Modern German. In Theoretical Linguistics and Grammatical Description, Robin Sackmann (ed.), 323-344. Amsterdam: Benjamins.

Wiese, Bernd (1999). Unterspezifizierte Paradigmen. Form und Funktion in der pronominalen Deklination. Linguistik Online 4, 3/99.

Wiese, Bernd (2001). Pronominale Deklination. Handout of talk at IDS Mannheim.

Williams, Edwin (1997). Blocking and anaphora. Linguistic Inquiry 28, 577-628.

Wunderlich, Dieter (1996). Minimalist morphology: The role of paradigms. In Yearbook of Morphology 1995, Geert Booij \& Jaap van Marle (eds.), 93-114. Dordrecht: Kluwer.

Wunderlich, Dieter (1997a). A minimalist model of inflectional morphology. In The Role of Economy Principles in Linguistic Theory, Chris Wilder, Hans-Martin Gärtner, \& Manfred Bierwisch (eds.), 267-298. Berlin: Akademie Verlag.

Wunderlich, Dieter (1997b). Der unterspezifizierte Artikel. In Sprache im Fokus, Christa Dürscheid, Karl Heinz Ramers \& Monika Schwarz (eds.), 47-55 Tübingen: Niemeyer.

Wunderlich, Dieter (1999). German noun plural reconsidered. Unpublished manuscript, Universität Düsseldorf.

Wurzel, Wolfgang Ullrich (1990). The mechanisms of inflection: Lexicon representations, rules, and irregularities. In Contemporary Morphology, Wolfgang Dressler et al. (eds.), 203-216. Berlin: Mouton de Gruyter.

Wurzel, Wolfgang Ullrich (1998). Drei Ebenen der Struktur von Flexionsparadigmen. In Models of Inflection, Ray Fabri, Albert Ortmann \& Teresa Parodi (eds), 225-241. Tübingen: Niemeyer.

Zifonun, Gisela (2001). Grammatik des Deutschen im europäischen Vergleich: Das Pronomen, Teil 1: Überblick und Personalpronomina. Mannheim: IDS working paper amades $4 / 01$.

Zifonun, Gisela, et al. (1997). Grammatik der deutschen Sprache. Berlin: de Gruyter.

Zwicky, Arnold (1986). German adjective agreement in GPSG. Linguistics 24, 957-990. 